\title{
Genome-wide association study for feed efficiency and growth traits in U.S. beef cattle
}

\author{
Christopher M. Seabury ${ }^{1 *}$, David L. Oldeschulte ${ }^{1}$, Mahdi Saatchi², Jonathan E. Beever ${ }^{3}$, Jared E. Decker ${ }^{4,5}$, \\ Yvette A. Halley ${ }^{1}$, Eric K. Bhattarai ${ }^{1}$, Maral Molaei ${ }^{1}$, Harvey C. Freetly ${ }^{6}$, Stephanie L. Hansen ${ }^{2}$, Helen Yampara-lquise ${ }^{4}$, \\ Kristen A. Johnson ${ }^{7}$, Monty S. Kerley ${ }^{4}$, JaeWoo Kim ${ }^{4}$, Daniel D. Loy², Elisa Marques ${ }^{8}$, Holly L. Neibergs ${ }^{7}$, \\ Robert D. Schnabel ${ }^{4,5}$, Daniel W. Shike ${ }^{3}$, Matthew L. Spangler ${ }^{9}$, Robert L. Weaber ${ }^{10}$, Dorian J. Garrick ${ }^{2,11}$ \\ and Jeremy F. Taylor ${ }^{4^{*}}$
}

\begin{abstract}
Background: Single nucleotide polymorphism (SNP) arrays for domestic cattle have catalyzed the identification of genetic markers associated with complex traits for inclusion in modern breeding and selection programs. Using actual and imputed Illumina 778K genotypes for 3887 U.S. beef cattle from 3 populations (Angus, Hereford, SimAngus), we performed genome-wide association analyses for feed efficiency and growth traits including average daily gain (ADG), dry matter intake (DMI), mid-test metabolic weight (MMWT), and residual feed intake (RFI), with marker-based heritability estimates produced for all traits and populations.

Results: Moderate and/or large-effect QTL were detected for all traits in all populations, as jointly defined by the estimated proportion of variance explained (PVE) by marker effects (PVE $\geq 1.0 \%$ ) and a nominal $P$-value threshold $(P \leq 5 \mathrm{e}-05)$. Lead SNPs with PVE $\geq 2.0 \%$ were considered putative evidence of large-effect QTL $(n=52)$, whereas those with PVE $\geq 1.0 \%$ but $<2.0 \%$ were considered putative evidence for moderate-effect QTL $(n=35)$. Identical or proximal lead SNPs associated with ADG, DMI, MMWT, and RFI collectively supported the potential for either pleiotropic QTL, or independent but proximal causal mutations for multiple traits within and between the analyzed populations. Marker-based heritability estimates for all investigated traits ranged from 0.18 to 0.60 using $778 \mathrm{~K}$ genotypes, or from 0.17 to 0.57 using 50K genotypes (reduced from Illumina 778K HD to Illumina Bovine SNP50). An investigation to determine if QTL detected by 778K analysis could also be detected using 50K genotypes produced variable results, suggesting that 50K analyses were generally insufficient for QTL detection in these populations, and that relevant breeding or selection programs should be based on higher density analyses (imputed or directly ascertained).

Conclusions: Fourteen moderate to large-effect QTL regions which ranged from being physically proximal (lead $\mathrm{SNPs} \leq 3 \mathrm{Mb}$ ) to fully overlapping for RFI, DMI, ADG, and MMWT were detected within and between populations, and included evidence for pleiotropy, proximal but independent causal mutations, and multi-breed QTL. Bovine positional candidate genes for these traits were functionally conserved across vertebrate species.
\end{abstract}

Keywords: GWAS, QTL, Feed efficiency and growth, Beef Cattle

\footnotetext{
*Correspondence: cseabury@cvm.tamu.edu; taylorjerr@missouri.edu ${ }^{1}$ Department of Veterinary Pathobiology, Texas A\&M University, College Station 77843, USA

${ }^{4}$ Division of Animal Sciences, University of Missouri, Columbia 65211, USA

Full list of author information is available at the end of the article
}

(c) The Author(s). 2017 Open Access This article is distributed under the terms of the Creative Commons Attribution 4.0 International License (http://creativecommons.org/licenses/by/4.0/), which permits unrestricted use, distribution, and reproduction in any medium, provided you give appropriate credit to the original author(s) and the source, provide a link to the Creative Commons license, and indicate if changes were made. The Creative Commons Public Domain Dedication waiver (http://creativecommons.org/publicdomain/zero/1.0/) applies to the data made available in this article, unless otherwise stated. 


\section{Background}

Feed efficiency analyses for beef cattle and other important food animals generally seek to relate measures of feed intake with measures of animal productivity (i.e., agricultural input versus output). Relevant to beef cattle production, and particularly among feedlot operations, the most costly component of the production process is feed, with feed-based expenditures during certain stages of production representing more than $80 \%$ of the total costs [1]. The overall economic importance of feed efficiency in beef cattle was initially recognized more than 40 years ago [2, 3], with modern improvements in the efficiency of feed utilization expected to yield positive economic returns across many facets of the beef industry $[1,4]$. Moreover, an estimated annual cost savings exceeding \$1 billion U.S. dollars could likely be achieved by increasing the efficiency of feed utilization by $10 \%$ in U.S. beef cattle alone [5].

Traditional measures of feed efficiency, such as the ratio of feed consumed to observed body weight gain (i.e., feed conversion ratio), are likely to be very successful in selecting for increased growth rates in beef cattle (i.e., increased producer income), but selection for enhanced weaning or yearling weights may also lead to increased costs associated with maintaining larger mature cows (i.e., increased nutrient requirements and feed costs; increased calving difficulty due to larger birth weights, etc) $[4,6,7]$. An alternative measure that has gained in popularity among livestock species is Residual Feed Intake (RFI), with this trait often defined as the difference between an animal's observed and expected feed intake in relation to the animal's body weight and growth rate during a specified feeding period (for review see [2, 4, 8-14]). The primary advantages of using RFI to estimate or measure feed efficiency include its phenotypic independence from daily gain as well as the traits used to calculate RFI, with previous heritability estimates among cattle populations ranging from 0.08 to 0.49 [8-10, 12, 13], thereby making RFI a preferred measure for dissecting the underlying biology related to feed efficiency, and for enabling genomic selection [13-15]. Given the economic importance of genomic selection for feed efficiency and growth traits in beef cattle, genome-wide association studies (GWAS) and/or linkage studies have now been performed (for review see [11, 16-20]), with the advent of the Illumina Bovine SNP50 Assay [21], and thereafter, the Illumina Bovine HD Assay [22] directly enabling most of these studies. However, a need remains to thoroughly investigate quantitative trait loci (QTL) associated with RFI as well as other feed intake and growth traits among U.S. beef cattle populations. Therefore, we used a single marker approach with relationship matrix and variance component analysis to map QTL associated with feedlot RFI, average daily dry matter intake
(DMI; lb/d), average daily gain on feed (ADG; lb/d), and mid-test metabolic body weight (MMWT; $\mathrm{lb}^{0.75}$ ) in U.S. Angus, Hereford, and SimAngus (Simmental $\times$ Angus) beef cattle [13], with corresponding heritability estimates produced for all investigated traits. Thereafter, we investigated whether QTL discovered using the Illumina BovineHD markers (hereafter 778K) were also detectable using the Illumina BovineSNP50 Assay (hereafter 50K), which is important for modern genomic selection programs predicated on historic $50 \mathrm{~K}$ analyses, and also compared the marker-based heritability estimates produced by the two arrays. Finally, we evaluated our $778 \mathrm{~K}$ results within the context of the established GWAS literature, and found some positional candidate genes underlying bovine feed efficiency and/or growth related QTL to be conserved across divergent food-animal species, with a tangible proportion of our bovine GWAS results also overlapping with specific loci implicated in studies of obesity or metabolic syndrome, diabetes, and insulin resistance among humans and/or mice. The results of this study are immediately useful for enabling genomic selection in beef cattle, but also suggest that domestic cattle may be relevant models for some human biomedical studies.

\section{Results and discussion}

\section{Heritability estimates for RFI, DMI, ADG, and MMWT}

Using a genomic relationship matrix [23] that was normalized using Gower's centering approach [24, 25], to yield a sampling variance of 1.0, we estimated the pseudoheritability $[24,25]\left[\left(\right.\right.$ i.e., $h_{a}^{2}=\sigma_{a}^{2} /\left(\sigma_{a}^{2}+\sigma_{e}^{2}\right)$; also represented as: $\left.h^{2}=\mathrm{V}_{\mathrm{A}} /\left(\mathrm{V}_{\mathrm{A}}+\mathrm{V}_{\mathrm{E}}\right)\right]$ for all investigated feed efficiency and growth traits (RFI, DMI, ADG and MMWT) in U.S. Angus, Hereford, and SimAngus cattle, thereby representing a major segment of the commercial U.S. beef industry (Table 1). The pseudo-heritability, as previously defined $[24,25]$, is the proportion of phenotypic variance that is explained by the marker-based genomic relationship matrix [23]. We used both the $50 \mathrm{~K}$ and the $778 \mathrm{~K}$ marker sets to construct relationship matrices [23]. Pseudo-heritability estimates obtained using the $778 \mathrm{~K}$ markers ranged from 0.18 to 0.60 across the investigated traits for the three beef cattle populations, with individual ranges of: $\mathrm{RFI}=0.20-0.49 ; \mathrm{DMI}=0.18-0.46$; ADG $=0.21-0.37 ; \mathrm{MMWT}=0.47-0.60$ (Table 1 ). These estimates are similar to those previously reported $[13,16,17$, 26], and are strongly correlated (Angus, all traits, $r=0.81$; Hereford, all traits, $r=0.99$; SimAngus, all traits, $r=0.77$ ) with previously obtained heritability estimates for the same populations [13]. An in silico reduction of the Illumina marker density from $778 \mathrm{~K}$ to $50 \mathrm{~K}$ (see Methods) for all populations yielded similar pseudo-heritability estimates across all traits $(r>0.99$, all traits; see Table 2$)$, suggesting that either SNP platform was suitable for 
Table 1 Variance component analysis with pseudo-heritability estimates $\left(h_{a}^{2}=\sigma_{a}^{2} /\left(\sigma_{a}^{2}+\sigma_{e}^{2}\right)\right.$; see references [24, 25]) representing the proportion of phenotypic variance explained by the 778K marker-based relationship matrix [23] for feed efficiency and component traits in U.S. beef cattle

\begin{tabular}{|c|c|c|c|c|c|c|c|c|c|}
\hline \multirow[b]{2}{*}{ Trait } & \multicolumn{3}{|c|}{ Angus } & \multicolumn{3}{|c|}{ Hereford } & \multicolumn{3}{|c|}{ SimAngus } \\
\hline & $\mathrm{h}^{2}$ & $V_{A}$ & $V_{E}$ & $\mathrm{~h}^{2}$ & $V_{A}$ & $V_{E}$ & $\mathrm{~h}^{2}$ & $V_{A}$ & $V_{E}$ \\
\hline $\mathrm{RFI}(\mathrm{Ib} / \mathrm{d})$ & 0.20 & 0.5821 & 2.3857 & 0.49 & 3.2584 & 3.4114 & 0.40 & 1.4600 & 2.2300 \\
\hline DMI (lb/d) & 0.18 & 0.9464 & 4.3881 & 0.46 & 4.3725 & 5.1484 & 0.26 & 1.4445 & 4.0500 \\
\hline ADG $(\mathrm{Ib} / \mathrm{d})$ & 0.21 & 0.0588 & 0.2273 & 0.28 & 0.1120 & 0.2862 & 0.37 & 0.0860 & $0.144 C$ \\
\hline MMWT $\left(\mathrm{Ib} \mathrm{b}^{0.75}\right)$ & 0.47 & 98.990 & 113.01 & 0.60 & 359.12 & 234.74 & 0.52 & 46.643 & 42.202 \\
\hline
\end{tabular}

marker-based heritability estimation. Across all populations (i.e., Angus, Hereford, and SimAngus), pseudoheritability estimates for feed efficiency and growth traits were highest among the Hereford beef cattle (Tables 1 and 2), which is likely due to a small number of contemporary groups and a uniform feeding regiment (see Methods) [13]. In contrast, both the Angus and SimAngus populations were used in nutritional trials, with each population possessing large numbers of contemporary groups, as previously described [13]. Nevertheless, moderate to high pseudo-heritability estimates obtained for feed efficiency and growth traits, particularly RFI and MMWT, further support the expectation of positive economic gains resulting from the implementation of genomic selection for feed efficiency traits in U.S. beef cattle, as evaluated using both multi-marker Bayesian models [13] and the single marker approaches [24, 25] applied in this study.

\section{EMMAX GWAS for RFI in U.S. Beef Cattle}

The results of our Illumina $778 \mathrm{~K}$ single-marker mixed model analyses for RFI are shown in Fig. 1. Statistical evidence for moderate or large effect QTL was observed for all populations $[13,24,25]$. Lead SNPs (i.e., the most strongly associated SNPs within a QTL region) with estimated proportion of variance explained (PVE; phenotypic) $[24,25] \geq 2.0 \%$ were considered putative evidence of large-effect QTL, whereas lead SNPs with PVE $\geq 1.0 \%$ but $<2.0 \%$ were considered putative evidence for moderateeffect QTL. Evaluation of all markers meeting the minimum Wellcome Trust significance threshold $(P<5 \mathrm{e}-05)$ [27] across all three populations revealed markers with PVE that ranged from $1.4 \%-3.3 \%$ (Additional file 1).
A summary of the largest effect QTL detected for RFI is provided in Table 3 .

Seven large-effect QTL (PVE > 2.0\%) distributed across seven autosomes were found in Angus using the $778 \mathrm{~K}$ data (Table 3). Most of the positional candidate genes either underlying or flanking the detected QTL (XIRP2, HSPB8, TOX/TRNAC-GCA, DDB1, DAK, ADPRHL1, $C D C$-16; see Table 3 ) have previously been associated with feed efficiency and growth in other livestock species (i.e., Angus cattle, broilers, domestic fowl, pigs), with components of obesity in humans, and are involved in the resumption of the human cell cycle following the S-phase checkpoint [28-37]. Moreover, one interesting positional candidate gene (lead SNP located within an intron of $D A K, 29 \_40 \mathrm{Mb}$, Table 3) produces the only known enzymatic source of riboflavin 4', 5' phosphate (cyclic flavin mononucleotide or FMN) [32], which acts as an electron acceptor in the oxidative metabolism of carbohydrates, amino acids, and fatty acids, but can also donate electrons to the electron transport chain $[38,39]$. This is important because riboflavin is known to be essential for energy production (i.e., via oxidative phosphorylation), growth, and development in a variety of species, including humans and livestock [32-35, 38, 39]. Additionally, because riboflavin depletion interferes with the normal progression of the cell cycle [38], the proximity of $D D B 1$ to $D A K\left(29 \_40 \mathrm{Mb}\right.$; Table 3 ) is also quite interesting considering that $D D B 1$ contributes to the checkpoint recovery process, and the resumption of the human cell cycle [31]. Among the seven large-effect RFI QTL detected in Angus, four (i.e., 2_30 Mb, 11_80 Mb, 14_27 Mb, 29_40 Mb;

Table 2 Variance component analysis with pseudo-heritability estimates $\left(h_{a}^{2}=\sigma_{a}^{2} /\left(\sigma_{a}^{2}+\sigma_{e}^{2}\right)\right.$; see references [24, 25]) representing the proportion of phenotypic variance explained by the 50K marker-based relationship matrix [23] for feed efficiency and component traits in U.S. beef cattle

\begin{tabular}{|c|c|c|c|c|c|c|c|c|c|}
\hline \multirow[b]{2}{*}{ Trait } & \multicolumn{3}{|c|}{ Angus } & \multicolumn{3}{|c|}{ Hereford } & \multicolumn{3}{|c|}{ SimAngus } \\
\hline & $\overline{h^{2}}$ & $V_{A}$ & $V_{E}$ & $\mathrm{~h}^{2}$ & $\mathrm{~V}_{\mathrm{A}}$ & $V_{E}$ & $\mathrm{~h}^{2}$ & $\mathrm{~V}_{\mathrm{A}}$ & $V_{E}$ \\
\hline $\mathrm{RFI}(\mathrm{lb} / \mathrm{d})$ & 0.20 & 0.5813 & 2.3865 & 0.49 & 3.2749 & 3.3685 & 0.37 & 1.3538 & 2.3228 \\
\hline DMI (lb/d) & 0.17 & 0.9033 & 4.4300 & 0.44 & 4.1279 & 5.3371 & 0.25 & 1.3792 & 4.1029 \\
\hline ADG (lb/d) & 0.19 & 0.0539 & 0.2318 & 0.27 & 0.1050 & 0.2900 & 0.38 & 0.0868 & 0.1425 \\
\hline MMWT $\left(\mathrm{Ib} \mathrm{b}^{0.75}\right)$ & 0.44 & 92.144 & 119.23 & 0.57 & 336.74 & 253.87 & 0.52 & 46.360 & 42.300 \\
\hline
\end{tabular}




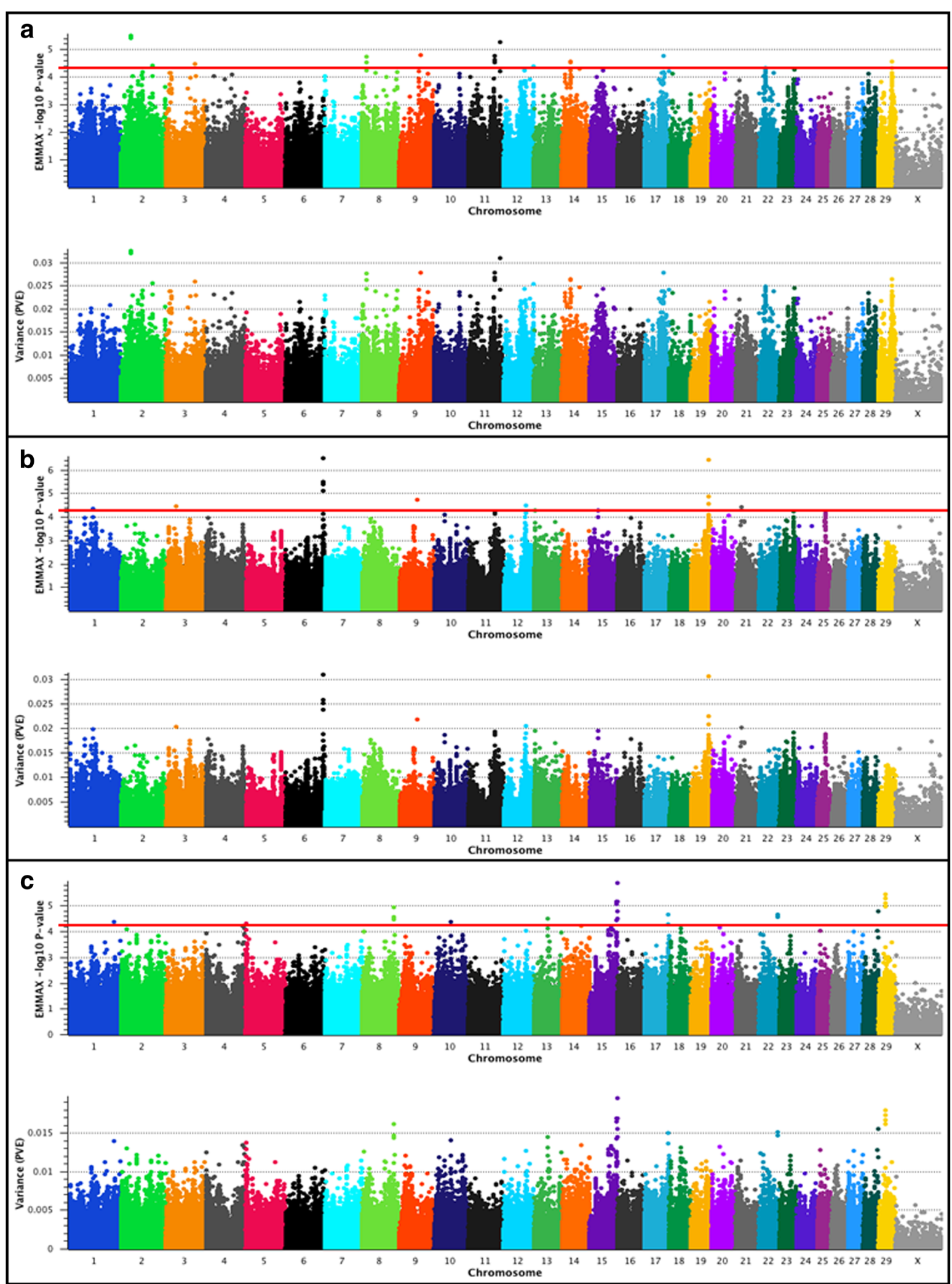

Fig. 1 (See legend on next page.) 
(See figure on previous page.)

Fig. 1 Residual feed intake (RFI) QTL. The top pane of each composite panel reflects a Manhattan plot with EMMAX - $\log _{10} P$-values for Illumina 778K markers, whereas the bottom pane depicts the estimated proportion of variance explained (PVE) by marker effects. Lead and supporting SNPs for moderate (1.0\% < PVE <2.0\%) or large-effect QTL (PVE $\geq 2.0 \%$ ) with $P \leq 5 \mathrm{e}-05$ and MAF $\geq 0.01$ are shown at or above the red line for U.S. Angus $(\mathbf{a} ; n=706)$, Hereford $(\mathbf{b} ; n=846)$, and SimAngus $(\mathbf{c} ; n=1217)$ beef cattle. The pseudo-autosomal region of BTAX is not depicted. A summary of all markers meeting the nominal significance level and MAF cutoff are presented in Additional File 1. Bovine 778K QTL criteria are described in Methods

Table 3) possessed lead SNPs with MAFs $\geq 0.26$, while three (i.e., 17_58 Mb, 8_13 Mb, 12_91 Mb; Table 3) possessed minor alleles at lower frequencies $(0.01<\mathrm{MAF}<0.06)$.

A difference between the present study and a Bayesian analysis (i.e., multi-marker $1 \mathrm{Mb}$ windows) recently reported for the same Angus population [13] was our use of only 706 Angus cattle (See Methods) for the investigation of RFI QTL. We limited our sample size for the RFI GWAS because many of the available Angus cattle were missing information about their age (i.e., birth dates), which negatively impacted our RFI variance component analysis using EMMAX [24, 25] (See Methods). Additionally, the 706 Angus cattle used to investigate RFI QTL in this study were all fed a uniform diet (See Methods). To determine whether proximally similar genomic regions (i.e., within $1 \mathrm{Mb}$ ) would be detected using both of the Illumina SNP assays routinely used for QTL discovery (i.e., $50 \mathrm{~K}$ and $778 \mathrm{~K})$, we conducted a second Angus RFI GWAS by rerunning EMMAX [24, 25] after reducing the marker density from $778 \mathrm{~K}$ to $50 \mathrm{~K}$. Subsequently, we observed that only five of the seven largest-effect Angus RFI QTL detected in the 778K analysis (2_30 Mb; 8_13 $\mathrm{Mb} ; 14 \_27 \mathrm{Mb} ; 29 \_40 \mathrm{Mb} ; 12 \_91 \mathrm{Mb}$; Table 3) were proximally replicated (i.e., within $\leq 1 \mathrm{Mb}$ ) among the top 100 ranked $50 \mathrm{~K}$ markers (i.e., with $P \leq 5 \mathrm{e}-05$ and/or PVE $\geq$ $1.0 \%$ ). Moreover, the 50K lead SNPs (i.e., $8 \_13 \mathrm{Mb}, 14 \_27$ $\mathrm{Mb}, 29 \_40 \mathrm{Mb}$ ) were physically proximal to the positions of the $778 \mathrm{~K}$ lead SNPs, supporting the prioritization of the same positional candidate genes as found in the $778 \mathrm{~K}$ analysis (Table 3).

Among U.S. Hereford cattle, analysis of RFI using the $778 \mathrm{~K}$ genotypes revealed evidence for four large-effect QTL (PVE Range: 2.0\% - 3.1\%; Table 3) distributed across four autosomes (6_113 Mb; 19_54 Mb; 3_29 Mb; 1_72 $\mathrm{Mb}$; see Table 3). Evaluation of the positional candidate genes implicated by our 778K analysis (DNAH17, RAB28, $D L G 1)$ revealed established associations with human obesity traits [40], adipogenic differentiation [41], type 1 diabetes and rheumatoid arthritis [27], and glucose uptake in mouse cells [42] (see Table 3). Notably, our

Table 3 Summary of the largest effect QTL detected for RFI in U.S. Angus, Hereford, and SimAngus beef cattle

\begin{tabular}{|c|c|c|c|c|c|c|}
\hline RFI & $\begin{array}{l}\text { Position } \\
\text { (Chr_Mb) }\end{array}$ & $\begin{array}{l}-\log _{10} \\
P \text {-value }\end{array}$ & Regression Beta & PVE & $\begin{array}{l}\text { Proximal Positional } \\
\text { Candidate Gene(s) }\end{array}$ & $\begin{array}{l}\text { Scientific Precedence [reference]; } \\
\text { organism; trait }\end{array}$ \\
\hline \multirow[t]{7}{*}{ Angus } & $2 \_30$ & 5.51 & 0.51 & 0.033 & XIRP2 & [28]; cattle; feed efficiency and growth \\
\hline & $11 \_80$ & 4.78 & -0.45 & 0.028 & NT5C1B/RDH1 & NA \\
\hline & $17 \_58$ & 4.77 & -1.01 & 0.028 & HSPB8 & [29]; human; obesity traits \\
\hline & 8_13 & 4.74 & -0.88 & 0.028 & LOC104969273/LOC104969276 & NA \\
\hline & $14 \_27$ & 4.56 & -0.43 & 0.027 & TOXIRNAC-GCA & [30]; human; adiposity \\
\hline & $29+40$ & 4.55 & 0.47 & 0.027 & $D D B 1 / D A K$ & $\begin{array}{l}\text { [31-35]; human, chicken, duck, pig; cell } \\
\text { cycle, feed efficiency and growth }\end{array}$ \\
\hline & 12_91 & 4.39 & 1.48 & 0.025 & ADPRHL1/CDC-16 & {$[36,37]$; chicken, pig; feed efficiency and growth } \\
\hline \multirow[t]{4}{*}{ Hereford } & $6 \_113$ & 6.51 & 1.03 & 0.031 & $R A B 28$ & [40]; human; obesity-related traits \\
\hline & $19 \_54$ & 6.45 & -0.55 & 0.031 & DNAH17 & [41]; human; adipogenic differentiation \\
\hline & 3_29 & 4.45 & -0.82 & 0.020 & PTPN22/RBSBN1 & [27]; human; diabetes, arthritis \\
\hline & 1_72 & 4.34 & 0.77 & 0.020 & $D L G 1$ & [42]; human; glucose uptake \\
\hline \multirow[t]{6}{*}{ SimAngus } & $15 \_84$ & 5.90 & -0.42 & 0.020 & STX3/MRPL16/GIF/TCN1 & $\begin{array}{l}\text { [43-46]; human, mice, cattle; obesity, glucose } \\
\text { levels, growth }\end{array}$ \\
\hline & $29 \_20$ & 5.46 & 0.58 & 0.018 & LOC101906936/LUZP2 & [47]; human; serum magnesium levels \\
\hline & $15 \_82$ & 5.16 & 0.39 & 0.017 & OR9Q2 & [50]; pig; feed efficiency \\
\hline & 8_97 & 4.96 & -0.56 & 0.016 & LOC101903458 & NA \\
\hline & 22_57 & 4.67 & -0.56 & 0.015 & TMEM40 & {$[11,49]$; cattle; feed efficiency } \\
\hline & $13 \_44$ & 4.51 & 0.58 & 0.014 & UCN3/CST7 & {$[53,54]$; mice, cattle; obesity } \\
\hline
\end{tabular}


single-marker approach replicated the Hereford largeeffect RFI QTL recently described on BTA19 (i.e., 19_54 Mb; Table 3) using a Bayesian multi-marker 1 $\mathrm{Mb}$ window approach [13], but provided positional candidate gene refinement, as the lead SNP in our analysis lies within an intron of DNAH17. Relevant to the potential contribution of these loci to selection, the MAFs for the lead SNPs defining the largest-effect RFI QTL detected in Hereford (i.e., 6_113 Mb; 19_54 Mb; 3_29 $\mathrm{Mb} ; 1$ 72 Mb; Table 3) were moderate to high (MAF Range $=0.07-0.35$ ), with the highest MAF corresponding to the QTL detected on BTA19. Following a reduction in marker content to $50 \mathrm{~K}$, we conducted a second Hereford RFI GWAS (See Methods) using EMMAX $[24,25]$ to determine whether the same QTL could be detected using the lower density array. Two of the four large-effect Hereford RFI QTL detected in the $778 \mathrm{~K}$ analysis (i.e., 6_113 Mb, 19_54 Mb; Table 3) were replicated among the 100 top-ranked markers associated in the 50K GWAS. Moreover, the two largesteffect Hereford RFI QTL replicated via 50K analysis were defined by lead SNPs that were either identical (i.e., $6 \_113 \mathrm{Mb}$ ) or physically proximal to the 778K lead SNPs (i.e., 19_54 Mb; Table 3), thereby supporting the prioritization of the same positional candidate genes.

For U.S. SimAngus cattle, our investigation of RFI using the $778 \mathrm{~K}$ genotypes produced statistical evidence for one large-effect (PVE $\geq 2.0 \%)$ and five moderateeffect $(1.0 \%<\mathrm{PVE}<2.0 \%)$ QTL distributed across five autosomes (Table 3). Evaluation of the top six SimAngus RFI QTL signals again revealed positional candidate genes that had previously been implicated in the modulation of traits related to obesity, diabetes, growth, and feed-efficiency (Table 3; Additional file 1). The lead SNP for the largest effect QTL (i.e., rs135481840; 15_84 Mb, Table 3) lies within an intergenic region between STX3, GIF and two adjacent genes (i.e., ncRNA LOC101907671, TCN1). Notably, STX3 is known to underlie a mouse QTL for serum glucose levels [43] and human studies have shown STX3 to be upregulated in obese subjects following physical exercise [44]. Moreover, both GIF and TCN1 are vitamin $\mathrm{B}_{12}$ (i.e., cobalamin) binding proteins and the mean body-weight gains for calves treated with vitamin $B_{12}$ have previously been observed to be superior to those that were untreated during the first 30 weeks of a feeding trial [45]. As was also found for our Hereford RFI QTL scan, a mitochondrial ribosomal protein gene (MRPL16) lies within $1 \mathrm{Mb}$ of the largest-effect SimAngus RFI QTL (Table 3), which may be biologically relevant in view of the proposed relationship between mitochondrial function and feed efficiency in livestock [46]. Other notable positional candidates (Table 3; Additional file 1) including LUZP2 (29_20 Mb), TMEM72 (28_45 Mb), and TMEM40 (22_57 Mb) have been associated with serum magnesium levels in humans [47] and feed efficiency and growth traits in cattle $[11,48,49]$. However, despite the biological support for the role of TMEM72 in RFI [48], only a single marker met the significance threshold for this QTL [27], suggesting caution in further considering a role for this putative QTL in selection or genetic evaluation models.

Interestingly, olfactory transduction pathways modulated by olfactory receptors are known to be associated with RFI in pigs [50], which is conceptually concordant with our detection of the positional candidate gene OR9Q2 (15_83 Mb; Table 3). We also observed that the largest-effect QTL region detected for RFI in SimAngus (15_84 Mb, Table 3) was flanked by eight olfactory receptor or receptor-like genes $(\leq 0.52 \mathrm{Mb}$ from the lead SNP rs135481840). An evaluation of all of the genomic regions that met the minimum significance threshold [27] (PVE Range $=1.4 \%-2.0 \%$ ) in the analysis of the $778 \mathrm{~K}$ genotypes revealed that multiple markers supported the six largest-effect SimAngus RFI QTL (Table 3), but that several other biologically relevant positional candidate genes were supported by only a single significant marker (Additional file 1). Positional candidate genes corresponding to several of these putative moderate-effect QTL $(\mathrm{PVE}<$ $2.0 \%$ ) have previously been associated with lipid metabolism and intramuscular fat deposition in chickens $(Y W H A H)$ [51], obesity traits in mice and humans (CST7, ADAM10) [52, 53] and RFI in cattle (CST7) [54] (Additional file 1). Analysis of the $50 \mathrm{~K}$ genotype set for RFI in SimAngus resulted in only two markers meeting the minimum significance threshold [27], and identified only one $\left(22 \_57 \mathrm{Mb}\right)$ of the six QTL that were detected in the $778 \mathrm{~K}$ analysis (Table 3). However, among the 100 top-ranked $50 \mathrm{~K}$ markers, we found evidence supporting three of the largest-effect SimAngus RFI QTL that were detected in the $778 \mathrm{~K}$ analysis (i.e., $\leq 1 \mathrm{Mb}$ from 22_57 Mb, 8_97 Mb, 15_83 Mb; Table 3).

\section{EMMAX GWAS for DMI in U.S. Beef Cattle}

Results of the single-marker mixed model analyses using 778K genotypes for DMI are shown in Fig. 2. Statistical evidence for moderate or large-effect DMI QTL was again observed for all of the investigated populations $[13,24,25]$. An evaluation of all markers meeting the minimum significance threshold $(P<5 \mathrm{e}-05)$ [27] across all three populations revealed estimates of PVE that ranged from $1.4 \%-3.9 \%$ (Additional file 1). Summary data for the largest effect QTL detected for DMI are provided in Table 4.

Among Angus, an investigation of the largest-effect DMI QTL (Table 4) detected using the 778K genotypes revealed at least seven biologically relevant positional candidate genes (Table 4) that have previously been associated with feed efficiency, diabetes, and obesity traits in livestock and humans, respectively [11, 55-62]. 


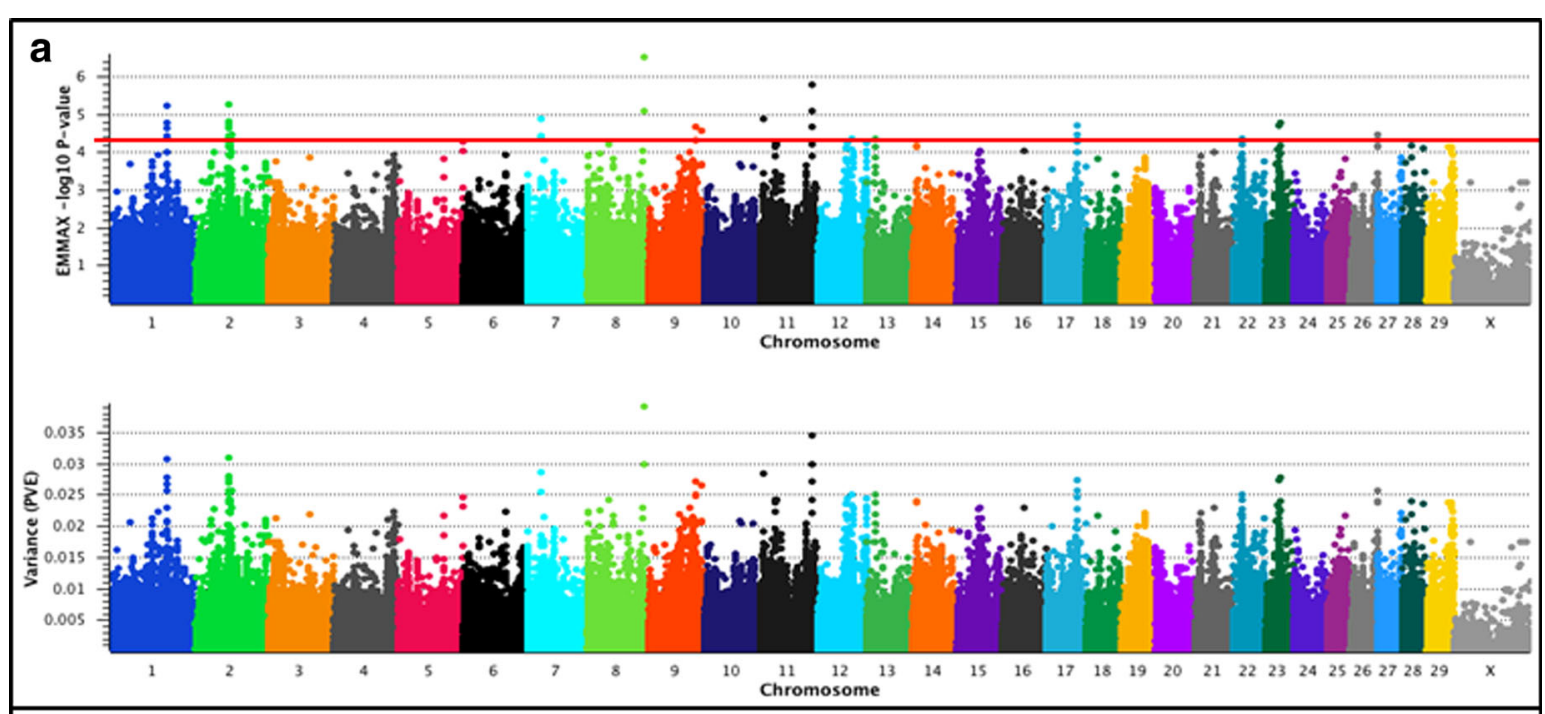

b
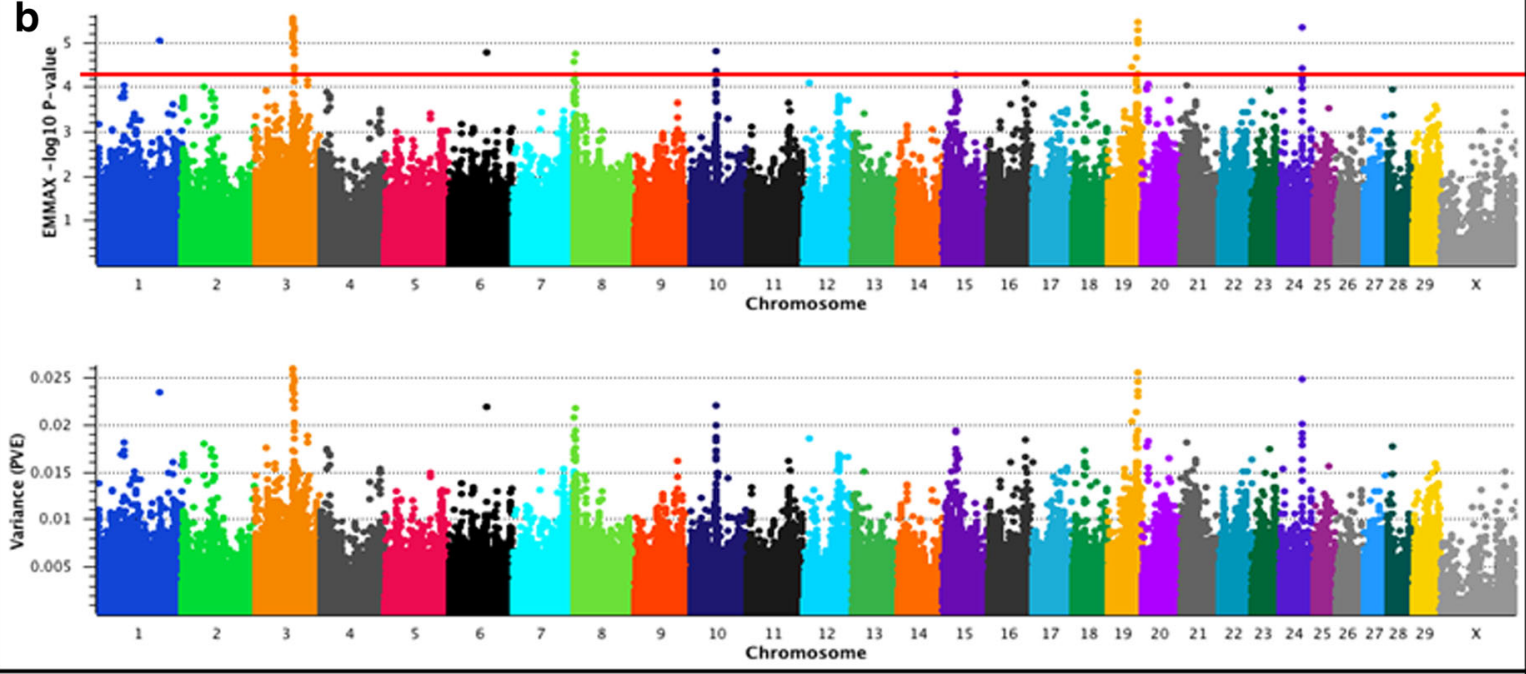

C

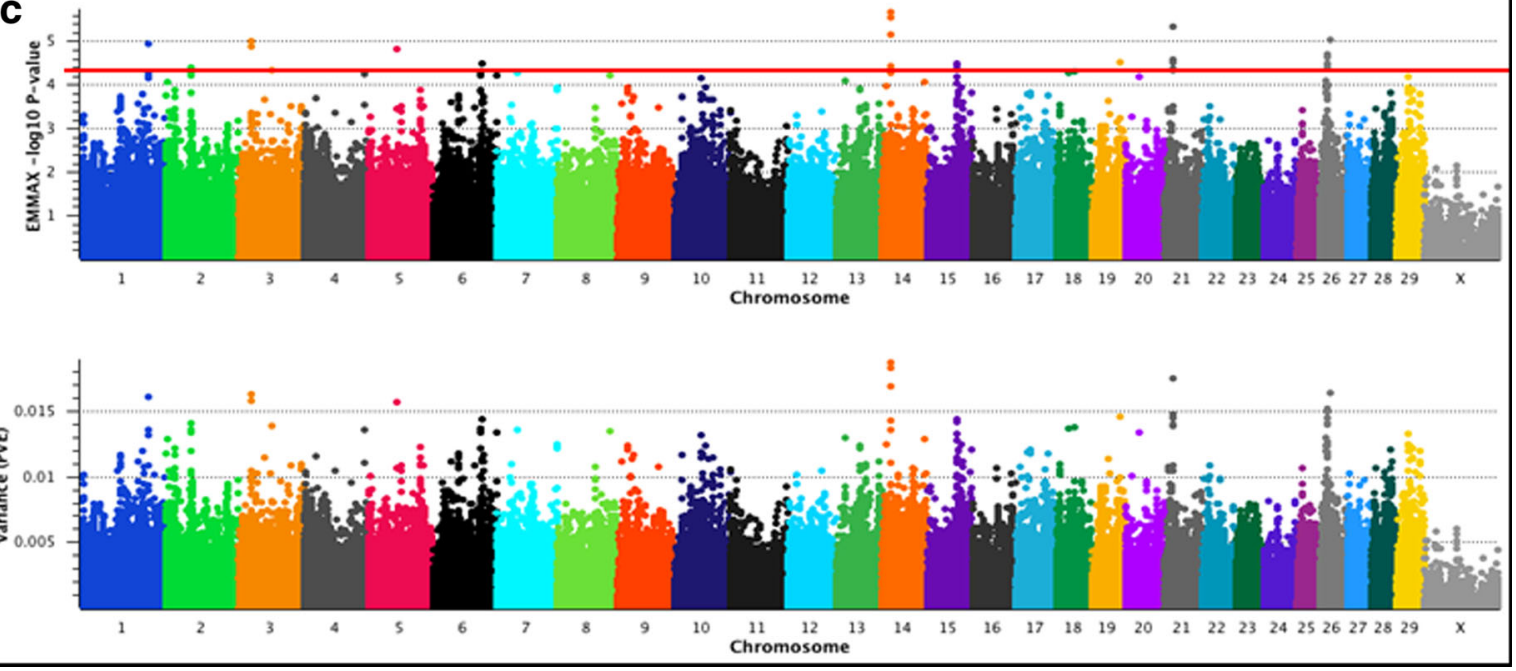

Fig. 2 (See legend on next page.) 
(See figure on previous page.)

Fig. 2 Dry matter intake (DMI) QTL. The top pane of each composite panel reflects a Manhattan plot with EMMAX - $\log _{10} P$-values for Illumina 778K markers, whereas the bottom pane depicts the estimated proportion of variance explained (PVE) by marker effects. Lead and supporting SNPs for moderate (1.0\% < PVE <2.0\%) or large-effect QTL (PVE $\geq 2.0 \%$ ) with $P \leq 5 \mathrm{e}-05$ and MAF $\geq 0.01$ are shown at or above the red line for U.S. Angus $(\mathbf{a} ; n=706)$, Hereford $(\mathbf{b} ; n=846)$, and SimAngus $(\mathbf{c} ; n=1218)$ beef cattle. The pseudo-autosomal region of BTAX is not depicted. A summary of all markers meeting the nominal significance level and MAF cutoff are presented in Additional File 1. Bovine 778K QTL criteria are described in Methods

For example, TNC (8_107 Mb; Table 4) has previously been reported to be differentially expressed between lowand high-RFI Angus cattle [55], and LMX1B (11_97 Mb; Table 4) has recently been implicated in human agerelated obesity, with obese subjects displaying decreased methylation with age [56]. Across the eight largest-effect DMI QTL revealed by the $778 \mathrm{~K}$ markers that met the minimum significance threshold [27] (PVE $\geq$ 2.0\%; Table 4), those located on BTA2 (2 $63 \mathrm{Mb})$, BTA1 (1_106 Mb), BTA11 (11_7 Mb), and BTA9 (9_90 Mb) were individually supported by the greatest numbers of markers (Additional file 1). Moreover, among the largesteffect Angus DMI QTL (Table 4), three positional candidate genes (CUX2, TMEM163, ESR1) have been associated with diabetes in humans $[57-59,61]$, while four (TNC, SLC12A2, IL1R2, ESR1) have been associated with aspects of feed efficiency and growth in cattle $[11,55]$ or adiposity in pigs [60]. Further investigation of all Angus DMI QTL regions detected in the $778 \mathrm{~K}$ analysis revealed several additional candidate genes of interest, including MGAT5 (2_63 Mb). Notably, Mgat $5^{-1-}$ null mice were previously shown to experience diminished glycemic response to

Table 4 Summary of the largest effect QTL detected for DMI in U.S. Angus, Hereford, and SimAngus beef cattle

\begin{tabular}{|c|c|c|c|c|c|c|}
\hline $\mathrm{DMl}$ & $\begin{array}{l}\text { Position } \\
\text { (Chr_Mb) }\end{array}$ & $\begin{array}{l}-\log _{10} \\
P \text {-value }\end{array}$ & Regression Beta & PVE & Proximal/Putative Candidate Gene(s) & $\begin{array}{l}\text { Scientific Precedence [reference]; } \\
\text { organism; trait }\end{array}$ \\
\hline \multirow[t]{8}{*}{ Angus } & 8_107 & 6.53 & -2.91 & 0.039 & LOC101902746/TNC & [55]; cattle; feed efficiency \\
\hline & 11_97 & 5.81 & 2.47 & 0.034 & MVB12B/LMX1B & [56]; human; obesity traits \\
\hline & $2 \_63$ & 5.26 & -0.74 & 0.031 & TMEM163/MGAT5 & $\begin{array}{l}{[58,59,62] \text {; human, mice; diabetes, }} \\
\text { nutrient sensing }\end{array}$ \\
\hline & 1_106 & 5.25 & 0.67 & 0.031 & LOC782622/LOC785220 & NA \\
\hline & 7_27 & 4.89 & -2.09 & 0.029 & $S L C 12 A 2$ & [11]; cattle; feed efficiency \\
\hline & $11 \_7$ & 4.88 & 0.89 & 0.028 & ILIR2 & [55]; cattle; feed efficiency \\
\hline & $17 \_57$ & 4.72 & 0.78 & 0.027 & CUX2 & [57]; human; diabetes \\
\hline & 9_90 & 4.68 & -0.57 & 0.027 & ESR1 & $\begin{array}{l}{[60,61] \text {; pig, human; feed efficiency, }} \\
\text { diabetes, obesity }\end{array}$ \\
\hline \multirow[t]{6}{*}{ Hereford } & 3_70 & 5.56 & 0.76 & 0.026 & $T Y W 3 / C R Y Z$ & [67]; human; insulin resistance \\
\hline & 19_55 & 5.48 & 0.79 & 0.026 & MGAT5B & [68]; mice; glycosylation \\
\hline & $24+41$ & 5.35 & -0.98 & 0.025 & $R A B 12$ & [69]; mice; cellular nutrient sensing \\
\hline & 3_73 & 5.35 & 0.98 & 0.025 & NEGR1 & $\begin{array}{l}\text { [70-72]; humans, rats; feed intake, } \\
\text { obesity }\end{array}$ \\
\hline & $19+57$ & 5.09 & -0.92 & 0.024 & RAB37 & [73]; mice; insulin release \\
\hline & $10 \_47$ & 4.81 & 0.91 & 0.022 & CA12/LACTB & $\begin{array}{l}{[74,75] \text {; humans, mice; pH balance, }} \\
\text { adiposity }\end{array}$ \\
\hline \multirow[t]{7}{*}{ SimAngus } & 14_17 & 5.68 & -1.05 & 0.019 & NDUFB9/RNF139/MTSS1/SQLE & $\begin{array}{l}{[28,82-85] \text {; cattle, human, mice; feed }} \\
\text { efficiency, diabetes, obesity }\end{array}$ \\
\hline & 21_16 & 5.36 & -0.49 & 0.018 & $S V 2 B$ & $\begin{array}{l}{[86,87] \text { human; insulin secretion and }} \\
\text { weight loss }\end{array}$ \\
\hline & 3_22 & 5.01 & -0.49 & 0.016 & LOC104971520/CHD1L/LOC788724/FMO5 & [88]; mice; obesity and diabetes \\
\hline & 26_14 & 4.70 & 0.50 & 0.015 & IDE/CYP26A1 & $\begin{array}{l}\text { [89-91]; humans, mice; insulin } \\
\text { degradation, diabetes, obesity }\end{array}$ \\
\hline & $15 \_58$ & 4.50 & 0.59 & 0.014 & CAPN5/MYO7A & $\begin{array}{l}{[92,93] \text {; cattle, chicken; meat }} \\
\text { tenderness; abdominal fat }\end{array}$ \\
\hline & 6_91 & 4.49 & -0.45 & 0.014 & CXCL1 & [94]; mice; diet-induced obesity \\
\hline & $2 \_47$ & 4.39 & -0.50 & 0.014 & LYPD6 & [55]; cattle; feed efficiency \\
\hline
\end{tabular}


exogenous glucagon, and increased insulin sensitivity [62]. Moreover, positional candidate genes associated with feeding behavior and growth in pigs (GATA3, GLRX3) $[15,63,64]$ as well as obesity traits in mice (IL17A) [65, 66] were also located within the Angus DMI QTL regions. Similar to our RFI analyses, differences between the results presented here and those previously reported for the same Angus population [13] primarily stem from our use of 706 Angus cattle $(n=$ 706 with age data and a uniform diet; See Methods) for the investigation of DMI QTL. The MAFs for all lead SNPs defining the eight largest-effect DMI QTL in Angus ranged from 0.01 (BTA8_107 $\mathrm{Mb}$ ) to 0.49 (BTA9_90 Mb), with five of the eight QTL having lead SNPs with MAFs $\geq 0.11$. We next analyzed DMI using $50 \mathrm{~K}$ genotypes and found evidence for three of the eight largest-effect QTL detected by $778 \mathrm{~K}$ analysis (11_97 Mb; 17_57 Mb; 9_90 Mb; Table 4). Moreover, among the 100 top-ranked $50 \mathrm{~K}$ markers, we found evidence for the replication of two additional Angus DMI QTL detected in the 778K analysis (2_63 Mb; 7_27 Mb; Table 4).

Evaluation of the largest-effect DMI QTL detected for Hereford in the $778 \mathrm{~K}$ analysis revealed at least five biologically relevant positional candidate genes (TYW3/ $C R Y Z, M G A T 5 B, R A B 12, R A B 37)$ that may harbor genetic variation influencing aspects of feed intake, including appetite (Table 4). The genomic region harboring TYW3 and CRYZ (3_70 Mb; Table 4) has previously been associated with insulin resistance (resistin) in humans [67], while Mgat $^{-1-}$ null mice exhibit increased insulin sensitivity [62]. The evolutionarily related gene family member and positional candidate MGAT5B (MGAT5 isozyme B or GnT-VB; 19_55 Mb) underlies the second largest-effect QTL detected for DMI in Hereford (Table 4). MGAT5 and MGAT5B are both known to be involved in the biosynthesis of N-glycans $[62,68]$, and both genes have been implicated as positional candidates for large-effect DMI QTL in Angus and Hereford (Table 4). Moreover, the positional candidate genes RAB12 (24_41 Mb), NEGR1 (3_73 $\mathrm{Mb})$, RAB37 (19_57 Mb), and CA12/LACTB (10_47 Mb) have also been associated with autophagy related to cellular nutrient sensing in mice [69], feed intake and/or obesity traits in humans and rats [70-72], insulin release in mice [73], hyponatremia in humans with loss of appetite and poor weight gain [74], and adiposity in humans [75] (Table 4). Importantly, the biochemical roles and pathway relationships between insulin and glucagon with respect to food intake, satiety, and body weight have been reported and reviewed, with both insulin and glucagon normally acting to reduce meal size $[76,77]$. The largeeffect Hereford DMI QTL detected on BTA3 $\left(3 \_70 \mathrm{Mb}\right)$ is generally compatible with a recent Bayesian analysis of these data which utilized $1 \mathrm{Mb}$ windows [13], but herein, we used single markers to identify specific positional candidate genes that were most proximal to the putative QTL peak(s), as defined by the lead SNP (Table 4). Investigation of all Illumina 778K markers meeting the minimum significance threshold [27] (PVE Range $=2.0 \%-2.6 \%$ ) provided additional support for $T Y W 3 / C R Y Z, M G A T 5 B$, $R A B 12, N E G R 1$, and $R A B 37$, but also revealed several other biologically relevant positional candidate genes with less marker-based support (i.e., only one SNP meeting the significance threshold; Additional file 1). For example, CORIN (BTA6_68 Mb) has previously been associated with body weight and obesity traits in mice $[78,79]$, while DNAH17 (BTA19_54 Mb), ANXA10 (BTA8_1 Mb) and $A A D A T\left(8 \_2 \mathrm{Mb}\right)$, have all been associated with aspects of feed efficiency and growth in either beef cattle or chickens [13, 80, 81] (Additional file 1). The MAFs for all lead SNPs defining the six large-effect DMI QTL in Hereford ranged from 0.15 (BTA24_41 Mb; BTA3_73 Mb; 19_57 Mb; $10 \_47 \mathrm{Mb}$ ) to 0.32 (BTA3_70 Mb). In the analysis of the $50 \mathrm{~K}$ genotype set three markers met the minimum significance threshold [27], and two (19_57 Mb, RAB37; 3_73 $\mathrm{Mb}, N E G R 1)$ supported large-effect QTL detected in the 778K analysis (i.e., within $1 \mathrm{Mb}$; Table 4). Moreover, SNPs proximal to all of the largest-effect Hereford DMI QTL detected in the $778 \mathrm{~K}$ analysis (Table 4) were observed among the 100 top-ranked 50K markers.

Analysis of DMI for the SimAngus cattle using the 778K genotypes revealed seven moderate-effect QTL $(1.0 \%<\operatorname{PVE}<2.0 \%)$ with at least ten biologically relevant positional candidate genes (NDUFB9, RNF139, MTSS1, SV2B, FMO5, IDE, CYP26A1, CAPN5, MYO7A, CXCL1, LYPD6, see Table 4). The largest-effect DMI QTL region (14_17 Mb; Table 4) included genes that have previously been associated with several aspects of feed efficiency (NDUFB9, RNF139) in beef cattle [28, 82] and Type 2 diabetes (MTSS1) in humans [83]. Moreover, all of the positional candidate genes near the largest-effect DMI QTL (14_17 Mb; Table 4) were also immediately flanked by SQLE (14_16.7 Mb), a cholesterol biosynthesis enzyme previously implicated as a primary positional candidate for a large-effect obesity QTL in mice $[84,85]$. Proximal to the second largesteffect SimAngus DMI QTL, we detected SV2B (21_16 $\mathrm{Mb}$; Table 4), which may be involved in aspects of regulated insulin secretion [86], and has been associated with human weight-loss across a diverse array of dietary regimes [87]. It should also be noted that previous studies also support the involvement of FMO5, IDE, CYP26A1, CAPN5, MYO7A, and CXCL1 (Table 4) in the manifestation of obesity traits in multiple vertebrate species (human, mice, poultry), in the onset of diabetes in humans, and/or in aspects of beef palatability [88-94]. Interestingly, while the DMI positional candidate gene MYO7A (15_57 Mb) has previously been associated with 
abdominal fat deposition in broilers, another proximal positional candidate gene (CAPN5, 15_57 Mb) has been associated with beef tenderness in Nelore cattle [92, 93]. Additionally, the lead SNP defining a DMI QTL on BTA2 (2_47 Mb; Table 4) was proximal to the transcriptional start site of LYPD6, which has previously been found to be differentially expressed between low- and high-RFI cattle [55]. An investigation of all $778 \mathrm{~K}$ markers that met the minimum significance threshold [27] (PVE Range $=1.4 \%-1.9 \%)$ revealed additional support for the seven moderate-effect DMI QTL (Additional file 1). Mixed model analysis of DMI in SimAngus using the 50K marker set revealed four markers that met the minimum significance threshold [27] and these corresponded to three of the six moderate-effect QTL detected in the 778K analysis (were $\leq 1 \mathrm{Mb}$ from 14_17 Mb, 21_16 Mb, 15_57 $\mathrm{Mb}$; Table 4). Further investigation of the 100 top-ranked $50 \mathrm{~K}$ markers revealed evidence for the replication of two additional QTL detected in the $778 \mathrm{~K}$ analysis (i.e., were $\leq 1 \mathrm{Mb}$ from 26_14 Mb and 3_22 Mb; Table 4).

\section{EMMAX GWAS for ADG in U.S. Beef Cattle}

Results of the $778 \mathrm{~K}$ single-marker mixed model analyses for ADG are presented in Fig. 3 and Table 5. Statistical evidence for moderate or large-effect QTL was observed for all of the investigated populations [13, 24, 25] with PVE that ranged from 1.1\% - 3.2\% (Additional file 1).

An investigation of the largest-effect ADG QTL detected in Angus in the $778 \mathrm{~K}$ analysis revealed at least 9 biologically relevant positional candidate genes (NOX3, OR4X1, SKAP2, ADAMTS19, SLC27A6, SLC12A2, PGMI, PITX2, EGF, Table 5) previously associated with livestock feed efficiency, insulin resistance, Type 1 diabetes, and adipogenesis in humans [11, 50, 95-102]. The largest-effect ADG QTL was detected on BTA9 (9_93 Mb) upstream of NOX3, which has previously been shown to modulate palmitate-induced insulin resistance in human hepatic cells [95]. We also detected an ADG QTL on BTA15 (15_79 Mb; OR4X1; Table 5), which was located within an olfactory receptor and receptor-like gene cluster. Olfactory receptors have previously been proposed as underlying feed efficiency QTL in pigs [50], and this QTL is proximal to the RFI QTL detected in SimAngus $(O R 9 Q 2$; Table 3) [13]. A moderate- effect ADG QTL detected on BTA4 (4_69 Mb) suggested only a single positional candidate gene (SKAP2) that has previously been confirmed to be associated with Type 1 diabetes in humans [97], and additional positional candidate genes underlying Angus ADG QTL on BTA7 (7_26 Mb; SLC12A2) and BTA3 (3_82 Mb; PGMI) have also been associated with feed efficiency in cattle and pigs, respectively $[11,100]$. We identified two positional candidate genes (PITX2, EGF; Table 5) for the ADG QTL detected on BTA6 (6_16 Mb). While PITX2 is known to be associated with stem cell commitment to adipogenesis in humans [101], EGF has been shown to regulate the absorption of nutrients and electrolytes from the small intestine of rabbits [102]. Evaluation of all genes proximal to the largest-effect ADG QTL detected in Angus revealed at least two additional positional candidate genes on BTA7 $\left(7 \_26 \mathrm{Mb}\right.$; ADAMTS19, SLC27A6; Table 5). Significant synergistic interactions have been reported between human genetic variation in ADAMTS19 and IGFR2 [98], whereas genetic variation in SLC27A6 has been associated with fatty acid composition of bovine milk [99]. The MAFs for all lead SNPs defining the six moderate-effect ADG QTL in Angus ranged from 0.24 (BTA6_16 Mb) to 0.45 (BTA7_26 Mb), with five of the six QTL having lead SNPs with MAFs $\geq 0.25$ (Additional file 1). The $50 \mathrm{~K}$ analysis produced seven markers that met the minimum significance threshold [27], which corresponded to three $\left(15 \_79 \mathrm{Mb} ; 3 \_82 \mathrm{Mb} ; 6 \_16 \mathrm{Mb}\right)$ of the six largest effect QTL detected by the $778 \mathrm{~K}$ analysis (Table 5 ). Evidence for the ADG QTL on BTA9 (9_93 Mb) was found among the nine top-ranked markers from the 50K analysis. Notably, the Angus ADG QTL detected on BTA4 (4_69 Mb) and BTA7 (7_26 Mb) in the 778K analysis were not supported by the locations of the top 100 ranked 50K markers.

Analysis of ADG in Hereford cattle using the 778K genotypes revealed at least eight biologically relevant positional candidate genes corresponding to seven large-effect QTL (PVE Range $=2.1 \%-3.1 \%$; Table 5) . Positional candidate genes proximal to the largesteffect QTL on BTA5 (5_106 Mb; FGF6, FGF23, $C C N D 2$; Table 5) have previously been associated with carcass muscle mass in Charolais cattle, blood-based markers for insulin resistance and obesity in humans, and insulin resistance versus sensitivity in human adipose tissue, respectively [103-105]. A large-effect QTL also was detected on BTA7 (7_93 Mb), for which we found one underlying positional candidate gene (ARRDC3) that has previously been associated with obesity in humans and mice [106]. Four additional large-effect ADG QTL signals were also detected on BTA8 (8_1 Mb; 8_4 Mb; 8_2 Mb) and BTA1 (1_144 $\mathrm{Mb}$; Table 5). Further evaluations of these QTL revealed positional candidate genes which have previously been associated with human adipocyte size (PALLD) [107] as well as feed efficiency and growth traits in cattle (GALNTL6) [108-110]; with a recent investigation providing some evidence for bovine copy number variants proximal to GALNTL6 [110]. Overlapping ADG and DMI QTL were detected on BTA8 (8_1 Mb; $8 \_2 \mathrm{Mb}$ ) in Hereford, with PALLD and AADAT being positional candidate genes for both traits. Notably, while $A A D A T$ has previously been associated with feed efficiency and growth traits in both poultry and seabass 


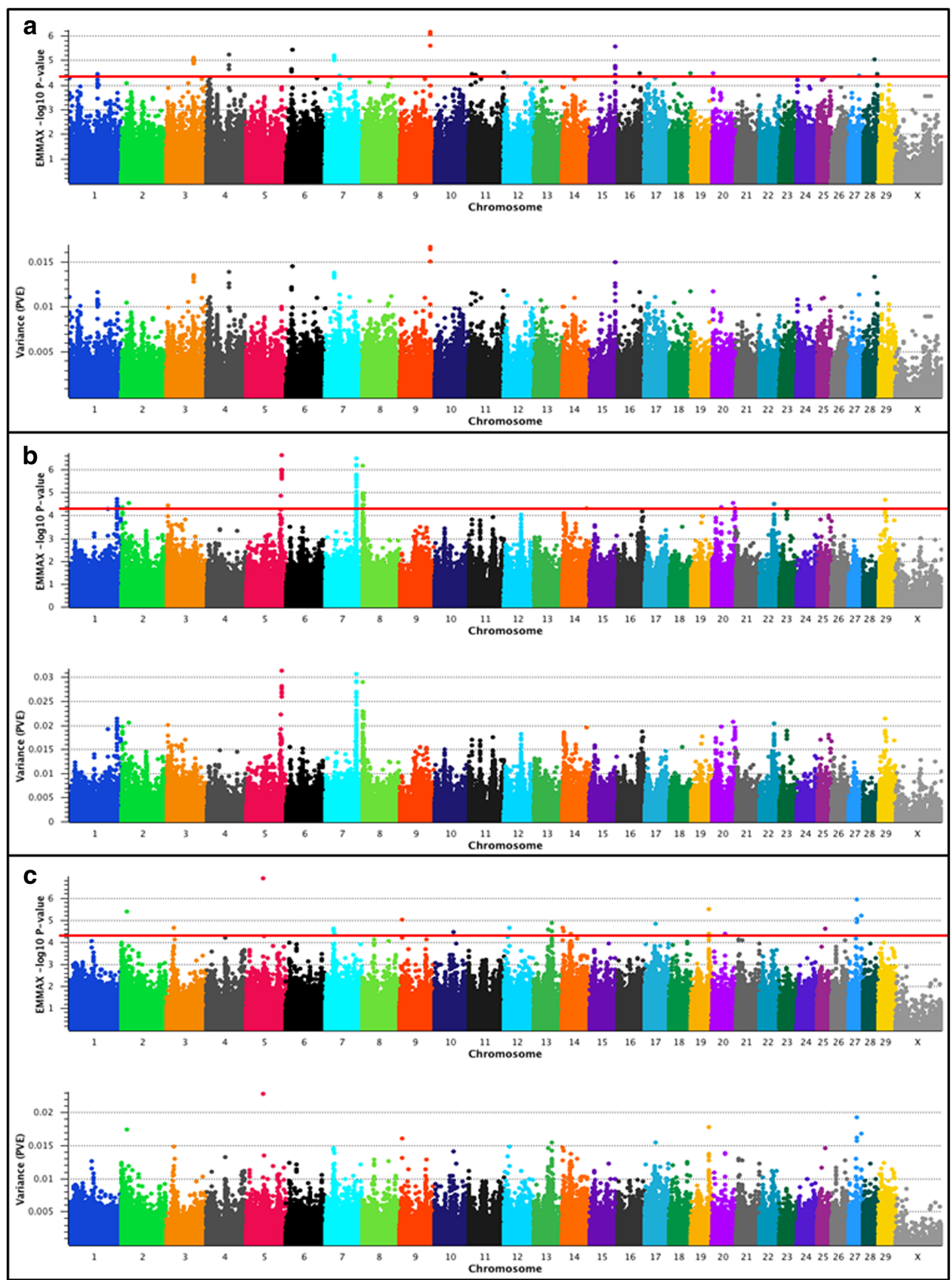

Fig. 3 (See legend on next page.) 
(See figure on previous page.)

Fig. 3 Average daily gain (ADG) QTL. The top pane of each composite panel reflects a Manhattan plot with EMMAX - $\log _{10} P$-values for Illumina 778K markers, whereas the bottom pane depicts the estimated proportion of variance explained (PVE) by marker effects. Lead and supporting SNPs for moderate (1.0\% < PVE <2.0\%) or large-effect QTL (PVE $\geq 2.0 \%$ ) with $P \leq 5 \mathrm{e}-05$ and MAF $\geq 0.01$ are shown at or above the red line for U.S. Angus (a; $n=1572)$, Hereford $(\mathbf{b} ; n=849)$, and SimAngus $(\mathbf{c} ; n=1237)$ beef cattle. The pseudo-autosomal region of BTAX is not depicted. A summary of all markers meeting the nominal significance level and MAF cutoff are presented in Additional File 1. Bovine 778K QTL criteria are described in Methods

$[81,111]$ (Table 5), the BTA8 QTL signals (8_1 Mb; 8_2 $\mathrm{Mb}$ ) for DMI in Hereford were limited to a single lead SNP underlying each QTL that met the minimum significance threshold [27] (Additional file 1). An investigation of the QTL on BTA1 revealed at least three biologically relevant positional candidate genes (ABCG1, TFF3, UBASH3A; Table 5). The ATP-binding cassette transporter protein encoded by $A B C G 1$ has unambiguously been shown to possess a major role in adiposity and fat mass growth in humans as well as mice [112], while increased levels of the intestinal protein encoded by TFF3 improved glucose tolerance in a diet-induced mouse obesity model [113]. Along the same lines, the positional candidate $U B A S H 3 A$ has previously been associated with marbling score in pigs [114], and is differentially methylated among peripheral blood leukocytes derived from lean and obese human adolescents [115]. Finally, we also detected a large-effect QTL on BTA2 (2_23 Mb;

Table 5 Summary of the largest effect QTL detected for ADG in U.S. Angus, Hereford, and SimAngus beef cattle

\begin{tabular}{|c|c|c|c|c|c|c|}
\hline ADG & $\begin{array}{l}\text { Position } \\
\text { (Chr_Mb) }\end{array}$ & $\begin{array}{l}-\log _{10} \\
P \text {-value }\end{array}$ & Regression Beta & PVE & Proximal/Putative Candidate Gene(s) & Scientific Precedence [reference]; organism; trait \\
\hline \multirow[t]{6}{*}{ Angus } & 9_93 & 6.16 & -0.11 & 0.017 & NOX3 & [95]; mice, human; insulin resistance \\
\hline & $15 \_79$ & 5.57 & -0.10 & 0.015 & OR4X1 & {$[50,96]$; pig, cattle; feed efficiency } \\
\hline & 4_69 & 5.22 & 0.11 & 0.014 & SKAP2/LOC101903616 & [97]; human; diabetes \\
\hline & 7_26 & 5.20 & -0.09 & 0.014 & SLC12A2/ADAMTS19/SLC27A6 & $\begin{array}{l}{[11,98,99] \text {; cattle, human, cattle; feed efficiency, }} \\
\text { interaction with IGF2R, fatty acid composition } \\
\text { in bovine milk }\end{array}$ \\
\hline & 3_82 & 5.10 & -0.10 & 0.013 & PGMI & [100]; pig; feed efficiency \\
\hline & $6 \_16$ & 4.64 & 0.10 & 0.012 & PITX2/EGF & $\begin{array}{l}{[101,102] \text {; human, rabbit; adipogenesis, regulated }} \\
\text { absorption of nutrients }\end{array}$ \\
\hline \multirow[t]{7}{*}{ Hereford } & 5_106 & 6.64 & -0.18 & 0.031 & FGF6/CCDN2/FGF23 & $\begin{array}{l}\text { [103-105]; cattle, human; muscle mass in carcass, } \\
\text { cell cycle regulation, insulin resistance and obesity }\end{array}$ \\
\hline & 7_93 & 6.51 & -0.15 & 0.031 & ARRDC3 & $\begin{array}{l}\text { [106]; human, mice; body mass and energy } \\
\text { expenditure }\end{array}$ \\
\hline & 8_1 & 6.17 & 0.17 & 0.029 & PALLD & [107]; human; adipocyte size \\
\hline & 8_4 & 4.96 & -0.15 & 0.023 & GALNTL6 & [108-110]; cattle; feed efficiency and growth \\
\hline & 8_2 & 4.82 & 0.13 & 0.022 & $\begin{array}{l}\text { LOC511409/LOC101904351/LOC520638/ } \\
\text { AADAT }\end{array}$ & $\begin{array}{l}{[81,111] \text {; chicken, seabass; feed efficiency and }} \\
\text { growth }\end{array}$ \\
\hline & $1 \_144$ & 4.71 & -0.45 & 0.021 & ABCG1/TFF3/TFF2/TFF1/UBASH3A & $\begin{array}{l}\text { [112-114]; human, mice, pig; obesity, glucose } \\
\text { tolerance, marbling score }\end{array}$ \\
\hline & $2 \_23$ & 4.53 & -0.25 & 0.021 & GPR155/SCRN3/SP9/OLA1 & $\begin{array}{l}\text { [50; } 116] \text { pig, cattle; feed efficiency; infectious } \\
\text { bovine keratoconjuctivitis }\end{array}$ \\
\hline \multirow[t]{7}{*}{ SimAngus } & $27 \_26$ & 5.93 & -0.15 & 0.019 & GTF2E2 & [117]; human; heart failure \\
\hline & $19 \_54$ & 5.52 & 0.10 & 0.018 & DNAH17/RBFOX3 & [41]; human; adipogenic differentiation \\
\hline & $13 \_53$ & 4.87 & 0.16 & 0.016 & SNORA70/STK35/PDYN/SIRPA & $\begin{array}{l}\text { [118-121]; human, cattle, mouse; diabetes, bovine } \\
\text { liver prohormone, mouse feeding behavior and } \\
\text { obesity traits, human adiposity }\end{array}$ \\
\hline & 3_22 & 4.67 & -0.10 & 0.015 & LOC104971520/CHD1L/LOC788724/FMO5 & $\begin{array}{l}{[88,122,123] \text {; mice, human; obesity and diabetes, }} \\
\text { cellular proliferation }\end{array}$ \\
\hline & 7_26 & 4.61 & 0.12 & 0.015 & ADAMTS19/SLC27A6 & $\begin{array}{l}\text { [98, 99]; human, cattle; interaction with IGF2R, fatty } \\
\text { acid composition in bovine milk }\end{array}$ \\
\hline & $14 \_7$ & 4.51 & -0.26 & 0.014 & LOC100848525/KHDRBS3 & {$[124,125]$; cattle; intramuscular fat } \\
\hline & 20_39 & 4.41 & 0.09 & 0.014 & RAl14 & {$[126,127] ;$ mice; obesity } \\
\hline
\end{tabular}


lead SNP 22.63 Mb; PVE = 2.1\%), with at least two relevant positional candidate genes suggested by the lead and supporting SNPs including GPR155, which has been associated with RFI in pigs [50], and OLA1, which has been associated with the incidence of infectious bovine keratoconjunctivitis in Angus cattle [116]. The results of our $778 \mathrm{~K}$ analysis are generally concordant with a recent Bayesian analysis that utilized $1 \mathrm{Mb}$ windows to investigate ADG QTL in U.S. Hereford cattle [13]; with our analysis further refining the positional candidate genes for large-effect QTL detected by both analyses on BTA5, BTA7, and BTA8. Moreover, we also provide evidence for additional ADG QTL on BTA8 (8_2 Mb; 8_4 Mb), BTA1 (1_144 Mb), and BTA2 (2_23 $\mathrm{Mb})$ that were not previously detected [13]. MAFs for all lead SNPs defining the six ADG QTL in Hereford ranged from 0.02 (BTA1_144 Mb) to 0.47 (BTA7_93 Mb). Reduction of the $778 \mathrm{~K}$ marker set to $50 \mathrm{~K}$ revealed eight markers that met the minimum significance threshold and provided evidence for the replication of QTL on BTA5 (5_106Mb), BTA7 (7_93 Mb), and BTA8 (8_1 Mb). Moreover, while ADG QTL signals detected by $778 \mathrm{~K}$ analysis on BTA8 (8_4 Mb) and BTA2 (2_23 Mb) were supported by the locations of the top 100 ranked $50 \mathrm{~K}$ markers, two QTL were not (i.e., 1_144 Mb; 8_2 Mb), indicating an inability to detect all relevant Hereford ADG QTL using the 50K marker set.

Seven moderate-effect ADG QTL $(1.0 \%>$ PVE $<2.0 \%)$ were detected in the $778 \mathrm{~K}$ SimAngus analysis, with three of these (3_22 Mb; 7_26 Mb; 19_54 Mb; Table 5) predicted to be proximal to, or overlap with, QTL detected for other traits or populations. For example, the SimAngus ADG QTL detected on BTA3 (3_22 Mb; Table 5) was also detected in the SimAngus DMI analysis (Table 4), suggesting either pleiotropy or that independent but proximal causal mutations influence ADG and DMI. Identical lead SNPs were found for both traits in SimAngus, which is concordant with a pleiotropic QTL. Further, the SimAngus ADG QTL detected on BTA7 (7_26 Mb; Table 5) was also detected in the analysis of ADG in Angus (Table 5), and was proximal $(\leq 1 \mathrm{Mb})$ to an Angus DMI QTL (7_27 $\mathrm{Mb}$; Table 4). These results were relatively unsurprising considering the Angus influence within this SimAngus population. While the lead SNPs defining the ADG and DMI QTL (7_26 Mb; 7_27 Mb) were not concordant in Angus, the direction of the SNP effects were concordant (Table 4; Table 5), suggesting either proximal but independent causal mutations, or the inability to accurately estimate a pleiotropic QTL position based on the Angus sample size for DMI $(n=706)$. Finally, the SimAngus ADG QTL detected on BTA19 (19_54 Mb) overlaps with one of the largest-effect QTL detected for RFI in Hereford (Table 3), and was also proximal ( $\leq 1.71 \mathrm{Mb} ; 19 \_55 \mathrm{Mb}$ ) to a Hereford DMI QTL (Table 4). Therefore, our analyses of these data suggests the existence of pleiotropic feed efficiency and growth QTL in U.S. beef populations that have not previously been reported [13]. Moreover, the overlap also suggests that positional candidate genes on BTA3 (CHD1L, FMO5; 3_22 Mb), BTA7 (ADAMTS19, SLC27A6; 7_26 Mb), and BTA19 (DNAH17, RBFOX3; 19_54 $\mathrm{Mb}$ ) may potentially hold biological value beyond selection for ADG in SimAngus cattle (Table 5), as overlapping or proximal genomic regions and corresponding positional candidate genes were identified during our analyses of RFI, DMI, and ADG for all three populations (see Tables 3-5).

Beyond the pleiotropic and multi-breed QTL described above, moderate-effect QTL for ADG were also detected on BTA27 (27_26 Mb), BTA13 (13_53 Mb), BTA14 (14_7 $\mathrm{Mb}$ ), and BTA20 (20_39 Mb) in SimAngus (Table 5). The QTL explaining the largest proportion of variance in ADG (BTA27_26 Mb) colocalized with the positional candidate gene GTF2E2, which has previously been associated with a metabolite (X-11787; hydroxy-leucine or hydroxyisoleucine) that is predictive of heart failure in African Americans [117]. Additionally, at least three positional candidate genes were identified (STK35, PDYN, SIRPA) for the ADG QTL on BTA13 (13_53 Mb). In particular, STK35, which is a nuclear Serine/Threonine kinase, is differentially expressed in the peripheral blood monocytes of Type 1 versus Type 2 diabetes patients [118], while $P D Y N$ (prodynorphin) is a prohormone that is differentially expressed in the livers of cattle exposed to differing nutritional statuses [119]. PDYN knockout affects feeding behavior, fasting weight loss, fat mass, and bone mineral content in mice [120], whereas SIRPA expression in human platelets was found to interact with obesity traits such as adiposity in a study of inflammatory proteins and artherosclerosis [121]. In regards to the overlapping SimAngus ADG and DMI QTL (3_22 Mb), FMO5 (BTA3_22 Mb) has been associated with obesity and diabetes in mice [88] and CHD1L is known to influence cellular proliferation $[122,123]$. Evaluation of the SimAngus ADG QTL on BTA14 (14_7 Mb) revealed an annotated positional candidate gene (KHDRBS3) that is associated with intramuscular fat deposition in cattle [124, 125]. A positional candidate gene (RAI14) for the ADG QTL on BTA20 (20_39 Mb), is associated with obesity in mice [126, 127]. Similarly, while the positional candidate gene DNAH17 (19_54 Mb) has also been associated with aspects of human adipogenesis (adipogenic differentiation) [40], a flanking positional candidate gene for this QTL (RBFOX3; Table 5) has been associated with serum urate levels in relation to human BMI [128]. The MAFs for all lead SNPs defining the seven moderateeffect ADG QTL in SimAngus ranged from 0.03 (BTA14_7 Mb) to nearly 0.50 (BTA3_22 Mb, MAF = 0.496), with five of the seven QTL having lead SNPs with 
MAFs $\geq 0.12$ (Additional file 1). After reducing the marker density from $778 \mathrm{~K}$ to $50 \mathrm{~K}$ and reanalyzing ADG, five markers met the minimum significance threshold [27], including evidence for QTL replication on BTA20 (20_39 Mb). Among the top 100 ranked 50K markers, we only found evidence for the replication of two additional SimAngus ADG QTL detected in the 778K analysis (27_26 Mb; 7_26 Mb), again underscoring an inability to detect ADG QTL using the reduced marker panel.

\section{EMMAX GWAS for MMWT in U.S. Beef Cattle}

Results of the $778 \mathrm{~K}$ single-marker mixed model analyses for MMWT are presented in Fig. 4 and Table 6. Evidence for moderate or large-effect QTL was observed for all of the populations with PVE that ranged from 1.1\%-4.6\% (Additional file 1).

Investigation of MMWT in Angus using the 778K genotype set revealed evidence for eight large-effect QTL (PVE $\geq 2.0 \%$ ) distributed across five autosomes (Table 6). The lead SNP defining the largest-effect QTL on BTA7 (7_24 Mb) explained $4.6 \%$ of the variance in MMWT, with the positional candidate gene ACSL6 directly underlying the QTL signal. This result is concordant with the previous Bayesian study employing $1 \mathrm{Mb}$ windows, in which ACSL6 was implicated for QTL underlying both DMI and MMWT [13]. In contrast, we place the Angus DMI QTL signal approximately $3 \mathrm{Mb}$ away from ACSL6, and approximately $2 \mathrm{Mb}$ from an ADG QTL (Tables 4, 5 and 6). It should also be noted that the largest-effect QTL detected for MMWT in Angus was also proximal to a SimAngus ADG QTL (7_26 Mb; Table 5). While ACSL6 has been identified as a strong positional candidate gene for feed efficiency and growth in Angus [13], it has also been implicated in diabetic myocardial metabolism in rodents, with evidence for ACSL6 being an insulin-regulated gene [129]. Among the eight large-effect MMWT QTL detected in Angus, three were located on BTA1 (1_98 Mb; 1_108 Mb; 1_133 Mb). Positional candidate genes (MYNN, ACTRT3; Table 6) which were proximal to the lead SNP at $98.5 \mathrm{Mb}$ on BTA1 have been implicated in obesity and diabetes traits in humans and mice, respectively $[130,131]$. Moreover, two proximally relevant positional candidate genes were also suggested by the locations of the lead SNPs for Angus MMWT QTL detected near $108 \mathrm{Mb}$ (PPM1L) and $133 \mathrm{Mb}$ (NCK1) on BTA1, with $P P M 1 L$ previously being associated with mouse obesity, metabolic syndrome, and growth [132], and NCK1 associated with glucose tolerance and insulin resistance in mice [133]. Other large-effect MMWT QTL were detected on BTA7 (7_0 Mb), BTA20 (20_72 Mb), BTA21 (21_13 Mb), and BTA18 (18_18 Mb; Table 6). Several positional candidate genes were proximal to the lead SNP defining a second BTA7 QTL (7_0 Mb; Table 6) for MMWT including CNOT6, which together with a related paralog, CNOT6L, has been associated with the regulation of human cell growth and survival [134, 135]. Additionally, at least four unannotated genes are also in close physical proximity to the lead SNP on BTA7, including an olfactory receptor like gene, two loci with similarity to CLEC7A (a C-type lectin domain superfamily member), one uncharacterized locus, and FLT4 which encodes a tyrosine kinase receptor for vascular endothelial growth factors $\mathrm{C}$ and $\mathrm{D}$ (Table 6).

Three positional candidate genes were identified for the Angus MMWT QTL detected on BTA20 (20_72 $\mathrm{Mb})$ and BTA21 (21_13 Mb) (Table 6). On BTA20, the lead SNP $(71.9 \mathrm{Mb})$ was proximal to PDCD6 and SLC9A3, which have been associated with muscle cell membrane repair in mice, and diet induced changes of the caprine rumen, respectively [136, 137]. The lead SNP for the Angus MMWT QTL on BTA21 (21_13 $\mathrm{Mb}$; Table 6) was adjacent to MCTP2 (13.24 Mb), which is known to be associated with human adiposity and obesity traits [138]. Additionally, two positional candidate genes for the MMWT QTL on BTA18 $\left(18 \_18 \mathrm{Mb}\right.$ ) have been associated with appetite regulation in the rat (CBLN1), and feed efficiency and growth in cattle (ZNF423) $[139,140]$. A final investigation of all Illumina $778 \mathrm{~K}$ markers that met or exceeded the Wellcome Trust significance threshold [27] revealed additional marker-based support for seven of the eight large-effect, and at least eight moderate-effect $(1.0 \% \leq$ PVE $\leq 2.0 \%$ ) MMWT QTL (i.e., 7_68 Mb; 8_80 Mb; 9_91 Mb; 10_44 Mb; 14_68 Mb; 17_35 Mb; 17_41 Mb; 19_42 Mb; Additional file 1). The directions of the marker effects were also consistently positive for all eight large-effect Angus MMWT QTL (Table 6), which was a unique observation among the three populations and traits analyzed in this study. The MAFs for all lead SNPs defining the eight large-effect MMWT QTL in Angus ranged from 0.06 (BTA18_18 Mb) to 0.20 (BTA7_24 Mb), with six of the eight QTL having lead SNPs possessing MAFs $\geq 0.11$. Reduction of the marker set from $778 \mathrm{~K}$ to $50 \mathrm{~K}$ revealed four markers that met or exceeded the Wellcome Trust significance threshold [27], but none of the markers identified the genomic regions harboring the eight largest-effect QTL signals detected in the $778 \mathrm{~K}$ analysis (Table 6). Among the top 100 ranked $50 \mathrm{~K}$ markers, there was no evidence to support the eight largest-effect Angus MMWT QTL.

Analysis of MMWT in Hereford using the 778K genotypes revealed evidence for nine large-effect QTL (PVE $\geq 2.0 \%$ ) distributed across six autosomes and BTAX (Table 6). The two largest-effect QTL were detected on BTAX (X_113 Mb; X_105 Mb), with lead SNPs $(112.90 \mathrm{Mb} ; 105.46 \mathrm{Mb})$ that were estimated to explain approximately $4.6 \%$ and $3.2 \%$ of the variance in MMWT. The location of the lead SNP near $113 \mathrm{Mb}$ 


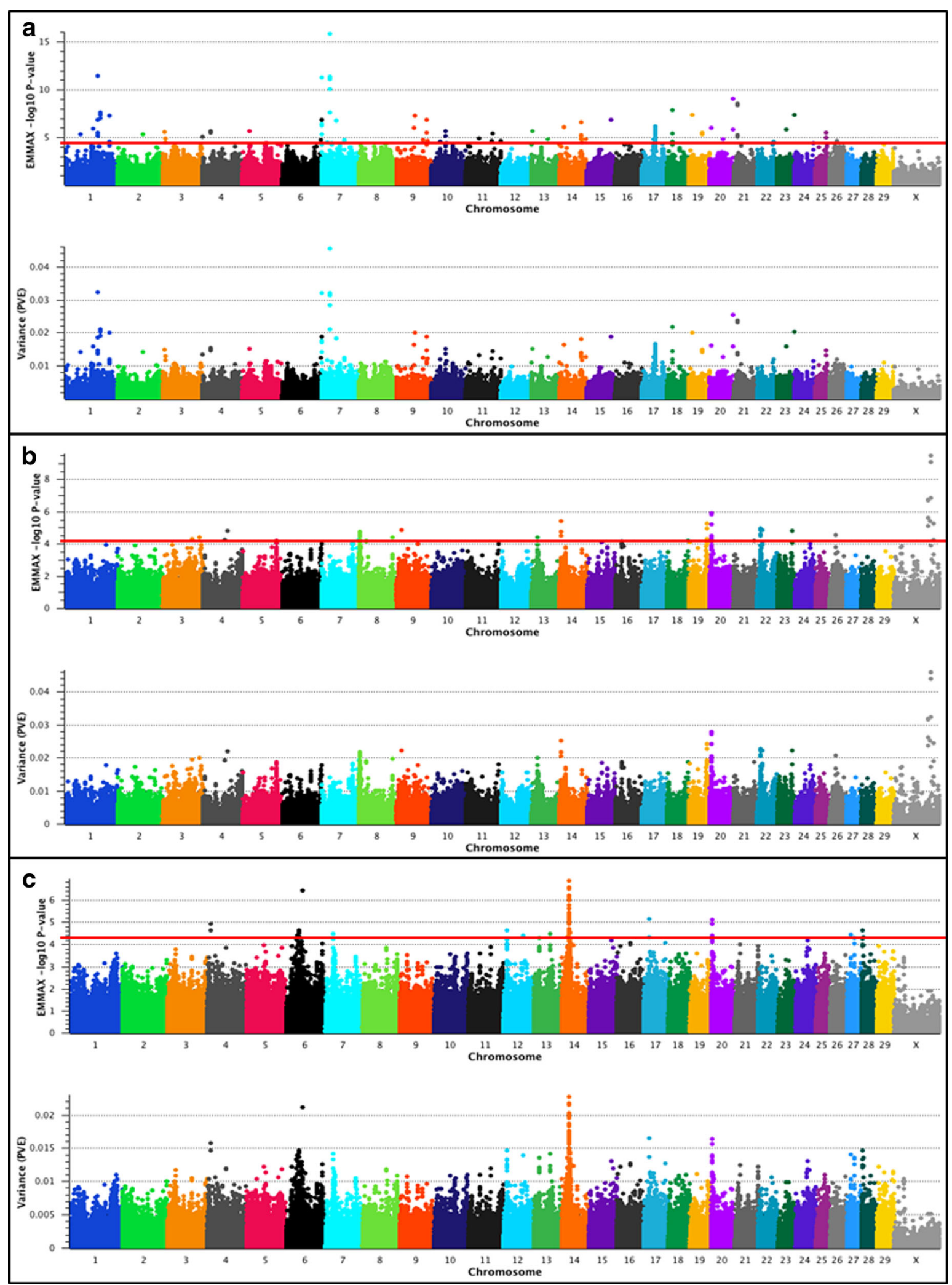

Fig. 4 (See legend on next page.) 


\section{(See figure on previous page.)}

Fig. 4 Mid-test metabolic weight (MMWT) QTL. The top pane of each composite panel reflects a Manhattan plot with EMMAX - $\log _{10} P$-values for Illumina 778K markers, whereas the bottom pane depicts the estimated proportion of variance explained (PVE) by marker effects. Lead and supporting SNPs for moderate $(1.0 \%<\mathrm{PVE}<2.0 \%$ ) or large-effect QTL (PVE $\geq 2.0 \%$ ) with $P \leq 5 \mathrm{e}-05$ and MAF $\geq 0.01$ are shown at or above the red line for U.S. Angus $(\mathbf{a} ; n=1572)$, Hereford $(\mathbf{b} ; n=849)$, and SimAngus $(\mathbf{c} ; n=1238)$ beef cattle. The pseudo-autosomal region of BTAX is not depicted. A summary of all markers meeting the nominal significance level and MAF cutoff are presented in Additional File 1. Bovine 778K QTL criteria are described in Methods

was upstream of the transcriptional start site of $M A G E B 16$, which is differentially expressed under high and low protein diets, and is associated with pathways related to cancer [141]. The primary positional candidate genes underlying the lead SNP on BTAX near 105 $\mathrm{Mb}$ were $M A O A$ and $M A O B$, which are associated with human obesity [142]. Moreover, the proposed mechanism of action by which $M A O A$ and $M A O B$ genotypes influence obesity relates to dopamine bioavailability, which is implicated in appetite regulation [142]. We also detected a MMWT QTL on BTA20 (20_5 Mb; lead SNP $4.90 \mathrm{Mb})$, which ranked third in our genome-wide analysis (PVE $=2.8 \%$, and for which we identified several biologically important positional candidate genes including STC2 and LOC101903982 (SYNPO2 like; Table 6). Notably, $S T C 2$ is an endoplasmic reticulum stress response gene that is associated with adiposity and obesity in nondiabetic humans [143], while SYNPO2 plays a role in early skeletal muscle development (myofibrillogenesis), and because of its association with myopathyrelated proteins, SYNPO2 is considered a candidate gene for muscle disease [144]. Beyond STC2, several additional genes encoding endoplasmic reticulum-related proteins (http://www.genecards.org) were also noted proximal to the MMWT QTL on BTA20 (20_5 Mb) including ERGIC1, CREBRF, and BNIP1 (Table 6).

Interestingly, most of the primary positional candidate genes for a large-effect QTL on BTA14 (14_6 Mb; lead SNP 6.02 Mb; PVE = 2.5\%) have been associated with aspects of feed efficiency and growth or obesity (Table 6) across three vertebrate species $[11,145,146]$. Specifically, $F A M 135 B$ has been associated with residual average daily gain (RADG) in SimAngus [11], and LRP12 is differentially expressed in the adipose tissue of divergently selected (lean versus fat) broiler lines [145] (Table 6). The biological significance of the positional candidate gene DPYS for the BTA14 (14_6 Mb) QTL stems from the fact that a deficiency in the enzyme encoded by this gene (dihydropyrimidinase) has been proposed to modulate growth retardation, failure to thrive, and other disadvantageous phenotypes in humans [146]. An evaluation of positional candidate genes colocalizing to the Hereford MMWT QTL on BTA19 (PVE $=2.4 \%$; lead SNP 55.67 $\mathrm{Mb}$ ) suggested that pleiotropic QTL influence both DMI and MMWT in Hereford (Tables 4 and 6), or that independent but proximal causal mutations influence the traits. While the lead SNPs identifying these QTL were not identical, they were proximally located $(\approx 141 \mathrm{~kb})$, implicating $M G A T 5 B$ as a positional candidate gene for both DMI and MMWT (Tables 4 and 6). While MGAT5B is involved in the biosynthesis of $\mathrm{N}$-linked and $\mathrm{O}$-mannosyl-linked glycosylation $[62,68]$, at least one prior investigation of this locus was catalyzed by the supposition that inactivation of the glycosyltransferases comprising the $O$ mannosyl processing pathway leads to human congenital disorders characterized by muscular atrophy with neuronal defects [68]. Additional positional candidate genes flanking the MMWT QTL on BTA19 include METTL23 and JMJD6 (Table 6). The protein encoded by METTL23 has methyltransferase activity and regulates a pathway underlying human cognition as well as GABPA function [147]. GABPA, which encodes a mitochondrial biogenesis and maintenance protein, was recently shown to be differentially expressed in the brown adipose tissue of mice subject to exercise, dietary restriction, and ephedrine treatment; with all such treatments resulting in weight loss as compared to controls [148]. Moreover, JMJD6, which encodes a nuclear protein involved in histone modification, transcription, RNA processing, and tissue development, was recently shown to have multiple roles in promoting adipogenic differentiation in mouse cells [149]. A large-effect MMWT QTL supported by 17 SNPs also was detected on BTA22 (lead SNP 11.03 Mb; PVE $=2.3 \%$ ), with ITGA9 implicated as a primary positional candidate gene. Notably, ITGA9 has recently been associated with RFI in dairy cattle [54].

For U.S. Hereford cattle, our analysis of MMWT again revealed the potential for proximal but independent causal mutations, or a pleiotropic QTL on BTA8 (8_2Mb) that influences ADG and MMWT (Table 5, Table 6), but that may also influence DMI (Additional file 1). While the lead SNP defining the Hereford MMWT QTL differed among the three traits, all were located upstream of the $A A D A T$ transcriptional start site, with the lead SNP for the MMWT QTL being most proximal to this positional candidate gene (BTA8 at $1.90 \mathrm{Mb}$ ). While we did not detect large-effect MMWT QTL for Hereford on BTA7 (7_93 Mb) or BTA18 (18_63 Mb) as previously described [13], we did replicate the QTL on BTA20 [13]; the only difference being that we defined QTL position (20_5 Mb) by rounding the position of the lead SNP $(4.90 \mathrm{Mb})$ to the nearest $\mathrm{Mb}$. One plausible explanation for the differences 
Table 6 Summary of the largest effect QTL detected for MMWT in U.S. Angus, Hereford, and SimAngus beef cattle

\begin{tabular}{|c|c|c|c|c|c|c|}
\hline MMWT & $\begin{array}{l}\text { Position } \\
\text { (Chr_Mb) }\end{array}$ & $\begin{array}{l}-\log _{10} \\
P \text {-value }\end{array}$ & $\begin{array}{l}\text { Regression } \\
\text { Beta }\end{array}$ & PVE & Proximal/Putative Candidate Gene(s) & $\begin{array}{l}\text { Scientific Precedence [reference]; } \\
\text { organism; trait }\end{array}$ \\
\hline \multirow[t]{8}{*}{ Angus } & 7_24 & 15.88 & 6.86 & 0.046 & ACSL6 & $\begin{array}{l}{[13,129] \text {; cattle, rodents; feed efficiency and }} \\
\text { growth; diabetic myocardial metabolism }\end{array}$ \\
\hline & 1_98 & 11.45 & 6.08 & 0.032 & MYNN/ACTRT3/LOC104970973/MECOM & $\begin{array}{l}{[130,131] \text {; human, mice; obesity and }} \\
\text { diabetes traits }\end{array}$ \\
\hline & 7_0 & 11.31 & 6.97 & 0.032 & $\begin{array}{l}\text { LOC100300983/LOC100125913/LOC101902704/ } \\
\text { LOC101902742/FLT4/CNOT6 }\end{array}$ & {$[134,135]$; human; cell growth } \\
\hline & $20 \_72$ & 9.12 & 4.89 & 0.025 & PDCD6/SLC9A3 & $\begin{array}{l}{[136,137] \text {; human and mice, goat; cell }} \\
\text { membrane repair and apoptosis, diet } \\
\text { induced changes in the rumen }\end{array}$ \\
\hline & 21_13 & 8.56 & 5.11 & 0.024 & MCTP2 & [138]; human; adiposity and obesity \\
\hline & 18_18 & 7.90 & 6.54 & 0.022 & CBLN1/C18H16orf78/ZNF423 & $\begin{array}{l}{[139,140] \text {; rat, cattle; appetite regulation, }} \\
\text { feed efficiency and growth }\end{array}$ \\
\hline & 1_108 & 7.64 & 5.29 & 0.021 & PPM1L & $\begin{array}{l}\text { [132]; mouse; obesity, metabolic syndrome, } \\
\text { and growth }\end{array}$ \\
\hline & 1_133 & 7.33 & 4.79 & 0.020 & NCK1 & $\begin{array}{l}\text { [133]; mouse; glucose tolerance and insulin } \\
\text { resistance }\end{array}$ \\
\hline \multirow[t]{9}{*}{ Hereford } & X_113 & 9.50 & 19.66 & 0.046 & MAGEB16/LOC786694 & $\begin{array}{l}\text { [141]; rat; diet induced differential expression } \\
\text { and potential risk for carcinogenesis }\end{array}$ \\
\hline & X_105 & 6.76 & 13.00 & 0.032 & MAOA/MAOB & [142]; human; obesity \\
\hline & $20 \_5$ & 5.96 & -3.76 & 0.028 & $\begin{array}{l}\text { STC2/LOC101903982/ERG/C1/RPL26L1/ATP6VOE1/ } \\
\text { CREBRF/BNIP1/NKX2-5 }\end{array}$ & $\begin{array}{l}{[143,144] \text {; human, mouse; adiposity and }} \\
\text { obesity, skeletal muscle development }\end{array}$ \\
\hline & $14 \_6$ & 5.44 & 9.24 & 0.025 & LOC104973978/FAM135B/LRP12/DPYS & $\begin{array}{l}{[11,145,146] \text {; cattle, chicken, human; feed }} \\
\text { efficiency and growth, obesity, growth } \\
\text { retardation }\end{array}$ \\
\hline & $19 \_56$ & 5.26 & 6.61 & 0.024 & MGAT5B/MFSD11/SRSF2/METTL23/JMJD6 & $\begin{array}{l}\text { [68, 147-149]; mice, human; glycosylation, } \\
\text { interaction with genes differentially expressed } \\
\text { in brown adipose, promoting adipogenic } \\
\text { differentiation. }\end{array}$ \\
\hline & 22_11 & 4.98 & 3.98 & 0.023 & ITGA9 & [54]; cattle; feed efficiency \\
\hline & $8 \_2$ & 4.63 & -3.87 & 0.021 & LOC101904351/LOC520638/AADAT & $\begin{array}{l}{[81,111] \text {; chicken, seabass; feed efficiency }} \\
\text { and growth }\end{array}$ \\
\hline & 26_19 & 4.55 & 6.99 & 0.021 & GOLGATB/CRTAC1 & $\begin{array}{l}{[150,151] \text {; buffalo, mice; dairy traits, lateral }} \\
\text { olfactory tract formation }\end{array}$ \\
\hline & X_145 & 4.40 & -3.90 & 0.020 & ANOS1 & $\begin{array}{l}{[152,153] \text {; human; puberty timing, serum }} \\
\text { and free testosterone }\end{array}$ \\
\hline \multirow[t]{9}{*}{ SimAngus } & $14 \_25$ & 6.89 & -2.73 & 0.023 & $\begin{array}{l}\text { LYN/RPS20/MOS/PLAG1/CHCHD7/SDR16C5/ } \\
\text { SDR16C6/PENK }\end{array}$ & $\begin{array}{l}\text { [154-156]; bovine, human; birthweight and } \\
\text { stature, height }\end{array}$ \\
\hline & $14 \_24$ & 6.61 & 2.61 & 0.022 & $\begin{array}{l}\text { LOC104974018/XKR4/TGS1/LYN/RPS20/MOS/ } \\
\text { PLAG1/CHCHD7/SDR16C5/SDR16C6/PENK }\end{array}$ & $\begin{array}{l}\text { [154-156]; bovine, human; birthweight and } \\
\text { stature, height }\end{array}$ \\
\hline & 17_18 & 5.15 & -1.91 & 0.017 & MAML3 & [157]; pig; downregulated in obese pigs \\
\hline & $20 \_5$ & 5.13 & 2.39 & 0.016 & $\begin{array}{l}\text { STC2/LOC101903982/ERG/C1/RPL26L1/ATP6VOE1/ } \\
\text { CREBRF/BNIP1/NKX2-5 }\end{array}$ & $\begin{array}{l}{[143,144] \text {; human, mouse; adiposity and }} \\
\text { obesity, skeletal muscle development }\end{array}$ \\
\hline & X_148 & 5.10 & -2.33 & 0.016 & NLGN4X & $\begin{array}{l}{[158,159] \text {; human; sex-biased exon usage, }} \\
\text { muscle and development pathways }\end{array}$ \\
\hline & 4_10 & 4.94 & 5.70 & 0.016 & HEPACAM2 & [160]; human; mitosis \\
\hline & $28 \_1$ & 4.64 & -1.74 & 0.015 & TAF5L/URB2 & $\begin{array}{l}{[161,162] \text {; human; diabetes, fasting insulin }} \\
\text { levels }\end{array}$ \\
\hline & 6_39 & 4.63 & 1.88 & 0.015 & LOC101904320/LCORL/NCAPG & $\begin{array}{l}{[163,164] \text {; cattle; feed efficiency and growth }} \\
\text { traits, body frame size }\end{array}$ \\
\hline & 14_26 & 4.51 & 2.08 & 0.014 & FAM110B/UBXN2B/NSMAF/TOX & [165]; cattle; Brahman puberty traits \\
\hline
\end{tabular}


Table 6 Summary of the largest effect QTL detected for MMWT in U.S. Angus, Hereford, and SimAngus beef cattle (Continued)

\begin{tabular}{|c|c|c|c|c|c|}
\hline 13_50 & 4.51 & 1.84 & 0.014 & $\begin{array}{l}\text { BMP2/LOC104973806/LOC104973807/ } \\
\text { LOC101904237/LOC104973808/LOC104973809 }\end{array}$ & $\begin{array}{l}\text { [166]; pig; loin muscle area, body size, and } \\
\text { structure traits }\end{array}$ \\
\hline 13_16 & 4.32 & -2.11 & 0.014 & $\begin{array}{l}\text { ITIH5/LOC104973716/LOC101903501/ } \\
\text { SFMBT2 }\end{array}$ & $\begin{array}{l}{[167,168] \text {; human; fasting insulin }} \\
\text { and BMI }\end{array}$ \\
\hline 27_22 & 4.32 & -3.45 & 0.014 & SGCZ & [41]; human; obesity-related traits \\
\hline
\end{tabular}

noted between the present study and a Bayesian $1 \mathrm{Mb}$ window analysis [13], was our inclusion of additional fixed effects within the mixed model (See Methods). Moreover, we also detected two large-effect MMWT QTL (26_19 $\mathrm{Mb}$; lead SNP $19.13 \mathrm{Mb} ; \mathrm{PVE}=2.1 \%$; X_145 Mb; lead SNP 145.33 Mb; PVE = 2.0\%) which were not previously detected [13] (Table 6). The two primary positional candidate genes GOLGA7B and CRTAC1 implicated by the lead and supporting SNPs on BTA26 (26_19 Mb) have been associated with dairy production traits in buffaloes, and lateral olfactory tract formation in mice [150, 151]. Investigation of the lead and supporting SNPs (Additional file 1) defining a third large-effect QTL detected on BTAX near $145 \mathrm{Mb}$ identified ANOS1 (i.e., previously KAL1) as the primary positional candidate gene (Table 6). ANOS1 has been associated with puberty timing in humans and serum testosterone levels in men; with this gene encoding an extracellular matrix protein implicated in the embryonic migration of gonadotrophin releasing hormone and olfactory-related neurons [152, 153]. The MAFs for all lead SNPs defining the nine large-effect MMWT QTL in Hereford ranged from 0.01 (BTAX_113 Mb) to 0.39 (BTA20_5 Mb), with seven of the nine QTL having lead SNPs possessing MAFs $>0.05$ (Additional file 1). Reduction of the marker content from $778 \mathrm{~K}$ to $50 \mathrm{~K}$ revealed 11 markers that met or exceeded the Wellcome Trust significance threshold [27], and included four of the nine largest-effect QTL that were detected in the $778 \mathrm{~K}$ analysis ( $\leq 1 \mathrm{Mb}$ from X_113 Mb; X_105 Mb; 20_5 Mb; 22_11 $\mathrm{Mb}$; Table 6). Further investigation of the 100 top-ranked $50 \mathrm{~K}$ markers revealed evidence supporting one additional large-effect QTL detected in the $778 \mathrm{~K}$ analysis $(\leq 1 \mathrm{Mb}$ from 19_56 Mb; Table 6).

Analysis of the 778K genotypes for U.S. SimAngus revealed evidence for two large-effect (PVE $\geq 2.0 \%$ ) and 10 moderate-effect $(1.0 \%>\mathrm{PVE}<2.0 \%)$ MMWT QTL (Table 6). The lead SNPs identifying the two largeeffect QTL on BTA14 (14_25 Mb, PVE $=2.3 \%$; 14_24 $\mathrm{Mb}, \mathrm{PVE}=2.2 \%$ ) were $\leq 590 \mathrm{~kb}$ apart (at $24.9 \mathrm{Mb}$ and $24.3 \mathrm{Mb}$ ). However, both QTL were supported by additional SNPs, including some that were located $\geq 1 \mathrm{Mb}$ apart (Additional file 1), suggesting that independent causal mutations influence MMWT in this region of BTA14 in SimAngus. At least eight biologically relevant positional candidate genes were identified within the QTL intervals spanning 14_25 $\mathrm{Mb}$ and 14_24 Mb
(Table 6), including LYN, RPS20, MOS, PLAG1, CHCHD7, SDR16C5, SDR16C6 and PENK. The genomic region harboring these genes is of particular interest considering previous associations with birth weight in Nellore cattle (LYN, RPS20, MOS, PLAG1, SDR16C5, SDR16C6, PENK), variation in adult human height (TGS1, LYN, RPS20, MOS, PLAG1, CHCHD7, SDR16C5, SDR16C6, $P E N K)$, and variation in body stature (hip-height) among beef and dairy cattle (PLAG1, CHCHD7, SDR16C5, SDR16C6) [154-156]. A moderate-effect MMWT QTL detected on BTA17 (17_18 Mb; lead SNP 18.04 Mb; PVE $=1.7 \%$ ) suggests a positional candidate gene (MAML3) that was associated with the degree of obesity (obesity index) in pigs during an expression QTL analysis [157]. As in Hereford, we also detected a MMWT QTL in SimAngus on BTA20 (20_5 Mb; lead SNP 4.91 Mb; PVE $=1.6 \%$; Table 6). The genomic location of this QTL physically overlaps between the two populations in this study, including some concordant supporting SNPs between the SimAngus MMWT QTL and the Hereford MMWT QTL (Additional file 1) whereby STC2 was implicated as the primary positional candidate gene (Table 6). This result is only partially concordant with the results of the Bayesian study employing non-overlapping $1 \mathrm{Mb}$ windows, in which STC2 was found to underlie a large-effect QTL for MMWT and RFI in Hereford, but was not implicated in MMWT in SimAngus [13]. While the previous study reported a SimAngus MMWT QTL on BTA20 (20_6 Mb), the identified $1 \mathrm{Mb}$ window was not concordant with the genomic positions of the lead and supporting SNPs from our analysis (lead SNP position $=4.91 \mathrm{Mb}$; range of supporting SNP positions $=4.87 \mathrm{Mb}$ to $4.91 \mathrm{Mb}, n=7$ supporting SNPs).

One moderate-effect MMWT QTL was detected on BTAX (X_148 Mb; lead SNP 147.54; PVE 1.6\%) in SimAngus, with $N L G N 4 X$ directly underlying both the lead and the supporting SNPs (Table 6). NLGN4X encodes a neuronal cell surface protein that is a member of the type-B carboxylesterase/lipase protein family, and has been observed to exhibit sex-biased exon usage across multiple developmental time points in humans, but has no known association with feed efficiency or growth [158]. However, NLGN4X knockdown in human neural stem cells significantly altered the expression of genes comprising several biologically relevant ontology groups including organ development (GO:0048513), 
muscle organ development (GO:0007517), muscle contraction (GO:0006936), tissue development (GO:0009888), regulation of cell morphogenesis (GO:0022604), epithelial cell differentiation (GO:0030855), and epithelium development (GO:0060429) [159]. The positional candidate gene HEPACAM2, which functions as a mitotic kinetics regulator, and likely also as a tumor suppressor gene, was found to directly underlie a moderate-effect SimAngus MMWT QTL on BTA4 (4_10 Mb; lead SNP $10.41 \mathrm{Mb}$; PVE 1.6\%; Table 6), with knockdown of HEPACAM2 expression in human cell lines resulting in mitotic arrest, disorganized spindles, and scattered chromosomes [160]. Relatively few positional candidate genes were identified for five additional moderate-effect MMWT QTL that were detected in SimAngus on BTA28 (28_1 Mb; lead SNP 0.68 Mb; PVE $=1.5 \%)$, BTA6 (6_39 Mb; lead SNP 39.25 Mb; PVE $=1.5 \%)$, BTA14 (14_26 Mb; lead SNP $26.28 \mathrm{Mb}$; PVE = $1.4 \%$ ), and BTA13 (13_50 Mb and 13_16 Mb; lead SNPs 49.96 Mb and 16.36 Mb; PVE = 1.4\%; See Table 6). On BTA28, the protein coding genes TAF5L and URB2 were most proximal to both the lead and the supporting SNPs defining this QTL. Human genetic variation in TAF5L, which is involved in myogenic transcription and differentiation, has been associated with risk for type-1 diabetes, while rare coding variants in $U R B 2$, a ribosome biogenesis gene, have been associated with fasting insulin levels in humans $[161,162]$. Relevant to feed efficiency and growth QTL recently detected and described [13], LOC101904320, LCORL, and NCAPG were proximal to the MMWT QTL on BTA6 (6_39 $\mathrm{Mb}$; Table 6). Both the lead and all supporting SNPs were located in a noncoding intergenic region flanking all three positional candidate genes. This result is interesting because $L C O R L$ and NCAPG have recently been reported to underlie a MMWT QTL in Angus that spanned two contiguous $1 \mathrm{Mb}$ windows identified by a Bayesian analysis (6_38 Mb; 6_39 Mb), and this genomic region is also known to harbor feed efficiency, growth, and carcass QTL (http://www.animalgenome.org/cgi-bin/QTLdb/BT/index) [13, 163, 164]. Four relevant positional candidate genes (FAM110B, UBXN2B, NSMAF, TOX) were identified for the MMWT QTL on BTA14 (14_26 Mb), with the lead SNP located in an intron of $U B X N 2 B$, a protein coding gene involved in endoplasmic reticulum biogenesis (Table 6). However, it should also be noted that FAM110B, NSMAF, and TOX have all previously been associated with puberty related traits in Brahman cattle, including age at formation of the first corpus luteum, and age at which scrotal circumference was $\geq 26 \mathrm{~cm}$ [165].

For the SimAngus MMWT QTL on BTA13 near 50 $\mathrm{Mb}$, the most proximal protein coding gene with reference annotation was $B M P 2$, while ITIH5 was determined to directly underlie the QTL near $16 \mathrm{Mb}$. We also noted that the transcriptional start site of SFMBT2 was proximal to both the lead and supporting SNPs that defined this QTL (13_16 Mb). Relevant to feed efficiency and growth, BMP2 has previously been associated with loin muscle area, body size, and structural traits in pigs, while ITIH5 and SFMBT2 have been associated with fasting insulin levels and BMI in humans, respectively [166-168]. Finally, the lead and supporting SNPs underlying the QTL on BTA27 (27_22 Mb) were found within an intron of SGCZ (lead SNP $21.70 \mathrm{Mb}$ ), which encodes a protein that bridges the inner cytoskeleton and the extra-cellular matrix, and has been associated with obesity-related traits in humans [41]. The MAFs for all lead SNPs defining the MMWT QTL detected in SimAngus ranged from 0.04 $\left(4 \_10 \mathrm{Mb}\right)$ to nearly $0.50\left(13 \_50 \mathrm{Mb}, \mathrm{MAF}=0.497\right)$, with 10 of the 12 QTL having lead SNPs possessing MAFs $\geq 0.15$ (Additional file 1). Following a reduction in marker content from $778 \mathrm{~K}$ to $50 \mathrm{~K}$, four markers met the Wellcome Trust significance threshold [27] for MMWT in SimAngus and supported the two largesteffect MMWT QTL detected in the $778 \mathrm{~K}$ analysis $(\leq 1$ $\mathrm{Mb}$ from 14_25 $\mathrm{Mb}$ and 14_24 Mb), and three moderateeffect QTL ( $\leq 1 \mathrm{Mb}$ from 6_39 Mb, 13_50 Mb, and 13_16 $\mathrm{Mb})$. Evaluation of the 100 top-ranked $50 \mathrm{~K}$ markers provided support for all of the other moderate-effect SimAngus MMWT QTL, with the exception of BTA4 (4_10 Mb).

\section{Conclusions}

We present evidence for both large (PVE $\geq 2.0 \%)$ and moderate-effect QTL $(1.0 \% \leq \mathrm{PVE} \leq 2.0 \%)$ that influence RFI, DMI, ADG, and MMWT in U.S. Angus, Hereford, and SimAngus beef cattle. Collectively, the positional candidate genes implicated by the QTL analyses for these populations suggest that feed efficiency and growth-associated loci are likely to be conserved across vertebrate species. Moreover, among the detected feed efficiency and growth QTL, we frequently observed positional candidate genes that had previously been associated with obesity-related traits or metabolic syndrome, biological aspects of adiposity, diabetes-related traits, and feed efficiency and growth traits across a variety of vertebrate species (humans, mice, rats, pigs, chickens, fish), which suggests both a relationship among phenotypes (i.e., feed efficiency, metabolic syndrome and adiposity) and a conserved biological system underlying feed intake and efficiency. Moreover, we detected 14 QTL regions within and between populations that ranged from being physically proximal $(\leq 3 \mathrm{Mb})$ to fully overlapping for RFI, DMI, ADG, and MMWT, suggesting the existence of pleiotropy, proximal but independent causal mutations influencing one or more of these traits, and some multibreed QTL (Additional file 1). For example, one such 3 Mb QTL interval (19_54 Mb to 19_57 Mb) was implicated in every analyzed trait (i.e., Hereford: RFI, DMI, MMWT; 
SimAngus: ADG). Finally, our comparison of the detection resolution limits for the $50 \mathrm{~K}$ versus the $778 \mathrm{~K}$ assays is important, particularly since many previous analyses have been performed using $50 \mathrm{~K}$ genotypes, with the results used to catalyze genetic progress in U.S. beef and dairy cattle. Herein, we demonstrate that while the $50 \mathrm{~K}$ and the $778 \mathrm{~K}$ produce very similar heritability estimates for RFI, DMI, ADG, and MMWT in our populations, some large and moderate-effect QTL go undetected in the 50K analysis, potentially reducing the opportunities for causal variant discovery. Therefore, additional QTL of moderate to large-effect will undoubtedly be discovered in historic data sets by imputing the data from $50 \mathrm{~K}$ to $778 \mathrm{~K}$ or beyond, and repeating previously performed analyses, which are also likely to produce further evidence for pleiotropy or multi-population segregation.

\section{Methods}

All feed efficiency and growth data were either collected by commercial producers or under the approval from the University of Missouri (ACUC Protocol 7505) or the University of Illinois at Champaign-Urbana (IACUC Protocols 06091 and 09078) Animal Care and Use Committees.

\section{Cattle populations, phenotypes, and genotypes}

All study animals, genotyping, and methods related to the ascertainment of phenotypes of interest such as ADG, daily average DMI, and MMWT, measured in Angus, Hereford, and SimAngus cohorts, were recently described [13]. Likewise, residual feed intake (RFI) was estimated by including partial linear regressions on ADG and MMWT in the model used to analyze DMI [13]. Using the available BovineHD genotypes previously described for the Angus, Hereford, and SimAngus cohorts, we conducted sample filtering by call rate $(<0.90)$, SNP filtering by call rate $(<0.85)$, and MAF filtering $(<0.001)$ as described by Saatchi and colleagues [13]. Details regarding the cattle included in the present study were as follows: (A) 1572 U.S. Angus steers were available for the analysis of ADG and MMWT, whereas 706 purebred Angus steers were used to analyze DMI and RFI (See Statistics for further details); (B) 850 U.S. Hereford cattle (826 steers, 24 heifers) were available for the analysis of ADG, DMI, MMWT, and RFI; (C) 1465 U.S. SimAngus steers were available for the analysis of ADG, DMI, MMWT, and RFI. For the 778K analyses, there were 722,716 SNPs for Angus, 659,688 SNPs for Hereford and 653,132 SNPs for SimAngus. All 50K analyses were performed following a populationspecific reduction in marker content from the filtered $778 \mathrm{~K}$ to $50 \mathrm{~K}$ density resulting in $47,582,48,728$, and 45,926 available markers for Angus, Hereford, and SimAngus respectively.

\section{Statistics}

Genome-wide association analyses were performed using a mixed linear model, implemented in EMMAX $[24,169-171]$, and were executed in Python as well as the SVS environment (Golden Helix, Version 7.7.6), as previously described $[169,170]$. The mixed model used in this study can be generally specified as: $y=X \beta+Z u+\epsilon$, where $y$ is a $n \times 1$ vector of the observed phenotypes, $X$ is a $n \times q$ matrix of fixed effects, $\beta$ is a $q \times 1$ vector representing the coefficients of fixed effects, and $Z$ is a $n \times t$ matrix relating instances of the random effect to the specified phenotypes [169, 170] (http://doc.goldenhelix.com/SVS/ 8.2.1/mixed_models.html). Moreover, we assume that $\operatorname{Var}(u)=\sigma_{g}^{2} \bar{K}$ and $\operatorname{Var}(\epsilon)=\sigma_{e}^{2} I$, such that $\operatorname{Var}(y)=\sigma_{g}^{2} Z K Z^{\prime}$ $+\sigma_{e}^{2} I$, but in the present study, $Z$ is simply the identity matrix $I$, and $K$ is a kinship matrix among all genotyped samples. To solve the mixed model equations using a generalized least squares approach, the variance components $\left(\sigma_{g}^{2}\right.$ and $\left.\sigma_{e}^{2}\right)$ must be estimated as previously described [24, 169, 171] (http://doc.goldenhelix.com/SVS/ 8.2.1/mixed_models.html). We used the REML-based EMMA approach to estimate variance components [24, 171], with stratification accounted for and controlled using the genomic kinship matrix [23] computed from either the filtered Illumina $778 \mathrm{~K}$ or $50 \mathrm{~K}$ genotypes. Models were evaluated using phenotypes and available data previously described [13], with final models parameterized to include the following: (A) Angus RFI included DMI as the dependent variable, with date of birth (DOB), contemporary group (CG), days on feed (DOF), ADG, and MMWT as covariates ( $n=706$ observations); Angus DMI included DOB, CG, and DOF as covariates $(n=706$ observations); Angus ADG included DOB (mean for missing values), percent Angus (i.e., not all were purebred), CG, and DOF as covariates ( $n=1572$ observations); Angus MMWT included DOB (mean for missing values), percent Angus (i.e., not all purebred), CG, and DOF as covariates ( $n=1572$ observations); Briefly, 706 purebred Angus were used for final RFI and DMI analyses because they possessed complete information regarding DOB, and were all fed a uniform diet; (B) Hereford RFI included DMI as the dependent variable, with $\mathrm{DOB}$, breed composition (i.e., not all were purebred), CG, sex, ADG, and MMWT as covariates $(n=846$ observations); Hereford DMI included DOB, breed composition, CG, and sex as covariates ( $n=846$ observations). Hereford ADG included DOB, breed composition, CG, and sex as covariates ( $n=849$ observations); Hereford MMWT included DOB, breed composition, CG, and sex as covariates $(n=$ 849 observations); (C) SimAngus RFI included DMI as the dependent variable, with DOB, breed composition, ranch, pen, experimental year, nutritional treatments (diet), DOF, slaughter group (SG), ADG, and MMWT as covariates ( $n=1217$ observations); SimAngus DMI included DOB, 
breed composition, ranch, pen, experimental year, nutritional treatments (diet), DOF, and SG as covariates $(n=$ 1218 observations); SimAngus ADG included DOB, breed composition, ranch, pen, experimental year, nutritional treatments (diet), DOF, and SG as covariates $(n=1237$ observations); SimAngus MMWT included DOB, breed composition, ranch, pen, experimental year, nutritional treatments (diet), DOF, and SG as covariates $(n=1238$ observations). All covariates were specified and treated as previously described [24]. Prior to analysis, all array genotypes were recoded as 0,1 , or 2 , based on the count of the minor allele for that animal at each SNP marker. For $778 \mathrm{~K}$ and $50 \mathrm{~K}$ analyses, markers were ranked by $P$-value and PVE. Bovine 778K QTL were defined by $\geq 2$ markers with $\mathrm{MAF} \geq 0.01$ (i.e., a lead SNP plus at least one supporting SNP within $1 \mathrm{Mb}$ ) which also met a nominal significance $(P \leq 5 \mathrm{e}-05)[27]$ and PVE $[24,25,169]$ threshold (PVE $\geq 1.0 \%$ ), and those QTL were evaluated, reported and discussed. However, a few putative QTL signals were presented for which only 1 lead SNP met all reporting criteria, and with one or more supporting SNPs falling below the nominal significance threshold (i.e., 28_45 Mb SimAngus RFI - TMEM72, $P<1 \mathrm{e}-04)$. For the 50K analyses, the following criteria were used to evaluate whether a 778K QTL was replicated: Among the top 100 ranked 50K SNPs, we required $\geq 1 \mathrm{SNP}$ to be within $1 \mathrm{Mb}$ of the $778 \mathrm{~K}$ lead SNP.

\section{Additional file}

Additional file 1: Summary data for all lead and supporting SNPs from the $778 \mathrm{~K}$ analyses for RFI, DMI, ADG, and MMWT, including dbSNP identifiers and QTL coordinates. (XLSX $710 \mathrm{~kb})$

\section{Acknowledgements}

This project was supported by National Research Initiative Competitive Grant number 2011-68004-30214 from the USDA National Institute of Food and Agriculture.

\section{Availability of data and materials}

The data sets supporting the results of this article are available for noncommercial purposes from JFT following the execution of a materials transfer agreement.

\section{Authors' contributions \\ Cattle were fed, relevant data were recorded and organized, and tissue samples were collected by RDS, JEB, HCF, SLH, HYI, KAJ, MSK, JWK, DDL, HLN, CMS, DWS, MLS and RLW. DNA was extracted and quantitated by JEB, HYI, JWK and RDS, and genotyped by EM. Data management, analysis and interpretation: CMS, MS, JED, RDS, DJG and JFT. GWAS and heritability estimates: CMS. QTL alignment and quality control analyses for positional candidate genes: CMS, DLO, YAH, EKB, and MM. Manuscript writing: CMS. All authors read and approved the final manuscript.}

\section{Competing interests}

The authors declare that they have no competing interests.

\section{Publisher's Note}

Springer Nature remains neutral with regard to jurisdictional claims in published maps and institutional affiliations.

\section{Author details}

'Department of Veterinary Pathobiology, Texas A\&M University, College Station 77843, USA. ${ }^{2}$ Department of Animal Science, lowa State University, Ames 50011, USA. ${ }^{3}$ Department of Animal Sciences, University of Illinois, Urbana 61801, USA. ${ }^{4}$ Division of Animal Sciences, University of Missouri, Columbia 65211, USA. Informatics Institute, University of Missouri, Columbia 65211, USA. ${ }^{6}$ USDA, ARS, US Meat Animal Research Center, Clay Center 68933, USA. ${ }^{7}$ Department of Animal Sciences, Washington State University, Pullman 99164, USA. ${ }^{8}$ GeneSeek a Neogen Company, Lincoln 68521, USA. ${ }^{9}$ Department of Animal Science, University of Nebraska, Lincoln 68583, USA. ${ }^{10}$ Department of Animal Sciences and Industry, Kansas State University, Manhattan 66506, USA. ${ }^{11}$ Institute of Veterinary, Animal and Biomedical Sciences, Massey University, Palmerston North, New Zealand.

Received: 26 October 2016 Accepted: 3 May 2017

Published online: 18 May 2017

\section{References}

1. Lowe M, Gereffi G. A value chain analysis of the U.S. beef and dairy industries. Center on Globalization, Governance \& Competitiveness. Duke University, Chapel Hill, North Carolina. 2009. http://www.cggc.duke.edu/ environment/valuechainanalysis/CGGC_Beef DairyReport_2-16-09.pdf. Accessed 19 Oct 2016

2. Koch RM, Swiger LA, Chambers D, Gregory KE. Efficiency of feed use in beef cattle. J Anim Sci. 1963;22:486-94.

3. Dickerson GE, Kunzi N, Cundiff LV, Koch RM, Arthaud VH, Gregory KE. Selection criteria for efficient beef production. J Anim Sci. 1974;39:659-73.

4. Archer JA, Richardson EC, Herd RM, Arthur PF. Potential for selection to improve efficiency of feed use in beef cattle: A review. Austr J Agric Res. 1999;50:147-62.

5. Weaber R, US Consortium for the Genetic Improvement of Feed Efficiency in Beef Cattle. National program for the genetic improvement of feed efficiency in beef cattle. 38 $8^{\text {th }}$ Int. Comm. For Anim. Rec. Sess., Cork, Ireland, 2012.

6. Strohbehn D, Bryce S, Maxwell D, Anderson L, Wilson D. Influence of Angus sire birth weight EPD on performance of crossbred first-calf heifers: A progress report. lowa State Beef Res. Rep. 1993;54-60.

7. Deutscher $\mathrm{GH}$. Reducing calving difficulty by heifer and sire selection and management. Proc. of the Range Beef Cow Symp. XIV, December 5-7, Gering: University of Nebraska-Lincoln; 1995.

8. Liu MF, Goonewardene LA, Bailey DRC, Basarab JA, Kemp RA, Arthur PF, et al. A study on the variation of feed efficiency in station tested beef bulls. Can J Anim Sci. 2000;80:435-41.

9. Arthur PF, Archer JA, Johnston DJ, Herd RM, Richardson EC, Parnell PF. Genetic and phenotypic variance and covariance components for feed intake, feed efficiency, and other postweaning traits in Angus cattle. J Anim Sci. 2001;79:2805-11.

10. Crowley JJ, MCGee M, Kenny DA, Crews Jr DH, Evans RD, Berry DP. Phenotypic and genetic parameters for different measures of feed efficiency in different breeds of Irish performance-tested beef bulls. J Anim Sci. 2010;88:885-94.

11. Serão NV, González-Peña D, Beever JE, Faulkner DB, Southey BR, RodriguezZas SL. Single nucleotide polymorphisms and haplotypes associated with feed efficiency in beef cattle. BMC Genet. 2013;14:94.

12. Lu D, Miller S, Sargolzaei M, Kelly M, Vander Voort G, Caldwell T, et al. Genome-wide association analyses for growth and feed efficiency traits in beef cattle. J Anim Sci. 2013;91:3612-33.

13. Saatchi M, Beever JE, Decker JE, Faulkner DB, Freetly HC, Hansen SL, et al. QTLs associated with dry matter intake, metabolic mid-test weight, growth and feed efficiency have little overlap across 4 beef cattle studies. BMC Genomics. 2014;15:1004

14. Kennedy BW, van der Werf JH, Meuwissen TH. Genetic and statistical properties of residual feed intake. J Anim Sci. 1993;71:3239-50.

15. Do DN, Ostersen T, Strathe AB, Mark T, Jensen J, Kadarmideen HN. Genomewide association and systems genetic analyses of residual feed intake, daily feed consumption, backfat and weight gain in pigs. BMC Genet. 2014;15:27.

16. Snelling WM, Allan MF, Keele JW, Kuehn LA, McDaneld T, Smith TPL, et al. Genome-wide association study of growth in crossbred beef cattle. J Anim Sci. 2010;88:837-48.

17. Bolormaa S, Hayes BJ, Savin K, Hawken R, Barendse W, Arthur PF, et al. Genome-wide association studies for feedlot and growth traits in cattle. J Anim Sci. 2011;89:1684-97. 
18. Barendse W, Reverter A, Bunch RJ, Harrison BE, Barris W, Thomas MB. A validated whole-genome association study of efficient food conversion in cattle. Genetics. 2007;176:1893-905.

19. Nkrumah JD, Sherman EL, Li C, Marques E, Crews Jr DH, Bartusiak R, et al. Primary genome scan to identify putative quantitative trait loci for feedlot growth rate, feed intake, and feed efficiency of beef cattle. J Anim Sci. 2007:85:3170-81.

20. Sherman EL, Nkrumah JD, Moore SS. Whole genome single nucleotide polymorphism associations with feed intake and feed efficiency in beef cattle. J Anim Sci. 2010;88:16-22.

21. Matukumalli LK, Lawley CT, Schnabel RD, Taylor JF, Allan MF, Heaton MP, et al. Development and characterization of a high density SNP genotyping assay for cattle. PLoS One. 2009;4:e5350.

22. Rincon G, Weber KL, Van Eenennaam AL, Golden BL, Medrano JF. Hot topic: performance of bovine high-density genotyping platforms in Holsteins and Jerseys. J Dairy Sci. 2011;94:6116-21.

23. VanRaden PM. Efficient methods to compute genomic predictions. J Dairy Sci. 2008;91:4414-23.

24. Kang HM, Sul JH, Service SK, Zaitlen NA, Kong SY, Freimer NB, et al. Variance component model to account for sample structure in genome-wide association studies. Nat Genet. 2010;42:348-54.

25. Segura V, Vihjálmsson BJ, Platt A, Korte A, Seren Ü, Long Q, et al. An efficient multi-locus mixed-model approach for genome-wide association studies in structured populations. Nat Genet. 2012;44:825-30.

26. Pryce JE, Arias J, Bowman PJ, Davis SR, Macdonald KA, Waghorn GC, et al. Accuracy of genomic predictions of residual feed intake and 250-day body weight in growing heifers using 625,000 single nucleotide polymorphism markers. J Dairy Sci. 2012:95:2108-19.

27. Wellcome Trust Case Control Consortium. Genome-wide association study of 14,000 cases of seven common diseases and 3,000 shared controls. Nature. 2007;447:661-78.

28. Connor EE, Kahl S, Elsasser TH, Parker JS, Li RW, Van Tassell CP, et al. Enhanced mitochondrial complex gene function and reduced liver size may mediate improved feed efficiency of beef cattle during compensatory growth. Funct Integr Genomics. 2010;10:39-51.

29. Ribeiro R, Monteiro C, Catalán V, Hu P, Cunha V, Rodríguez A, et al. Obesity and prostate cancer: gene expression signature of human periprostatic adipose tissue. BMC Med. 2012;10:108.

30. Fox CS, Liu Y, White CC, Feitosa M, Smith AV, Heard-Costa N, et al. Genomewide association for abdominal subcutaneous and visceral adipose reveals a novel locus for visceral fat in women. PLoS Genet. 2012;8:e1002695.

31. Leung-Pineda V, Huh J, Piwnica-Worms H. DDB1 targets Chk1 to the Cul4 E3 Ligase complex in normal cycling cells and in cells experiencing replication stress. Cancer Res. 2009;69:2630-7.

32. Cabezas A, Costas MJ, Pinto RM, Couto A, Cameselle JC. Identification of human and rat FAD-AMP lyase (cyclic FMN forming) as ATP-dependent dihydroxyacetone kinases. Biochem Biophys Res Commun. 2005;338:1682-9.

33. Deyhim F, Belay T, Teeter RG. An evaluation of dietary riboflavin supplementation on growth rate, feed efficiency, ration metabolizable energy content, and glutathione reductase activity of broilers. Nutr Res. 1992;12:1123-30.

34. Tang J, Wen ZG, Guo ZB, Huang W, Guo YM, Xie M, et al. Dietary riboflavin supplementation improve the growth performance and antioxidant status of starter white Pekin ducks fed a corn-soybean meal diet. Livest Sci. 2014 170:131-6.

35. Hughes $\mathrm{EH}$. The minimum requirement of riboflavin for the growing pig. J Nutr. 1940;20:233-8

36. Kong BW, Song JJ, Lee JY, Hargis BM, Wing T, Lassiter K, et al. Gene expression in breast muscle associated with feed efficiency in a single male broiler line using a chicken 44K oligo microarray. I. Top differentially expressed genes. Poult Sci. 2011;90:2535-47.

37. Fontanesi L, Galimberti G, Calò DG, Fronza R, Martelli PL, Scotti E, et al. Identification and association analysis of several hundred single nucleotide polymorphisms within candidate genes for back fat thickness in Italian Large White pigs using a selective genotyping approach. J Anim Sci. 2012; 90:2450-64.

38. Powers HJ, Corfe BM, Nakano E. Riboflavin in development and cell fate Subcell Biochem. 2012;56:229-45.

39. Henriques BJ, Olsen RK, Bross P, Gomes CM. Emerging roles for riboflavin in functional rescue of mitochondrial $\beta$-oxidation flavoenzymes. Curr Med Chem. 2010;17:3842-54.
40. Comuzzie AG, Cole SA, Laston SL, Voruganti VS, Haack K, Gibbs RA, et al. Novel genetic loci identified for the pathophysiology of childhood obesity in the Hispanic population. PLoS ONE. 2012;7:e51954.

41. Söhle J, Machuy N, Smailbegovic E, Holtzmann U, Grönniger E, Wench H, et al. Identification of new genes involved in human adipogenesis and fat storage. PLoS ONE. 2012;7:e31193.

42. Dhurandhar EJ, Dubuisson O, Mashtalir N, Krishnapuram R, Hegde V, Dhurandhar NV. E4orf1: a novel ligand that improves glucose disposal in cell culture. PLoS ONE. 2011;6:e23394.

43. Cheverud JM, Ehrich TH, Hrbek T, Kenney JP, Pletscher LS, Semenkovich CF. Quantitative trait loci for obesity- and diabetes-related traits and their dietary responses to high-fat feeding in LGXSM recombinant inbred mouse strains. Diabetes. 2004;53:3328-36.

44. Abu-Farha M, Tiss A, Abubaker J, Khadir A, Al-Ghimlas F, Al-Khairi I, et al. Proteomics analysis of human obesity reveals the epigenetic factor HDAC4 as a potential target for obesity. PLoS ONE. 2013;8:e75342.

45. Judson GJ, McFarlane JD, Riley MJ, Milne ML, Horne AC. Vitamin B12 and copper supplementation in beef calves. Aust Vet J. 1982;58:249-52.

46. Bottje WG, Carstens GE. Association of mitochondrial function and feed efficiency in poultry and livestock species. J Anim Sci. 2009;87:E48-63.

47. Meyer TE, Verwoert GC, Hwang SJ, Glazer NL, Smith AV, van Rooij FJ, et al. Genetic factors for osteoporosis consortium; Meta analysis of glucose and insulin related traits consortium. Genome-wide association studies of serum magnesium, potassium, and sodium concentrations identify six loci influencing serum magnesium levels. PLoS Genet. 2010;6:e1001045

48. Yao C, Spurlock DM, Armentano LE, Page Jr CD, VandeHaar MJ, Bickhart DM, et al. Random forests approach for identifying additive and epistatic single nucleotide polymorphisms associated with residual feed intake in dairy cattle. J Dairy Sci. 2013:96:6716-29.

49. Serão NV, González-Peña D, Beever JE, Bollero GA, Southey BR, Faulkner DB, et al. Bivariate genome-wide association analysis of the growth and intake components of feed efficiency. PLOS ONE. 2013;8:e78530.

50. Do DN, Strathe AB, Ostersen T, Pant SD, Kadarmideen HN. Genome-wide association and pathway analysis of feed efficiency in pigs reveal candidate genes and pathways for residual feed intake. Front Genet. 2014;5:307.

51. Cui HX, Liu RR, Zhao GP, Zheng MQ, Chen JL, Wen J. Identification of differentially expressed genes and pathways for intramuscular fat deposition in pectoralis major tissues of fast-and slow-growing chickens. BMC Genomics. 2012;13:213.

52. Moest H, Frei AP, Bhattacharya I, Geiger M, Wollscheid B, Wolfrum C. Malfunctioning of adipocytes in obesity is linked to quantitative surfaceome changes. Biochim Biophys Acta. 1831;2013:1208-16.

53. Chissoe S. Genes associated with obesity. United States Patent Application Publication. Pub. No.: US 2008/0108080 A1, 2008.

54. Hou Y, Bickhart DM, Chung H, Hutchison JL, Norman HD, Connor EE, et al. Analysis of copy number variations in Holstein cows identify potential mechanisms contributing to differences in residual feed intake. Funct Integr Genomics. 2012;12:717-23.

55. Chen Y, Gondro C, Quinn K, Herd RM, Parnell PF, Vanselow B. Global gene expression profiling reveals genes expressed differentially in cattle with high and low residual feed intake. Anim Genet. 2011:42:475-90.

56. Almén MS, Nilsson EK, Jacobsson JA, Kalnina I, Klovins J, Fredriksson R, et al. Genome-wide analysis reveals DNA methylation markers that vary with both age and obesity. Gene. 2014;548:61-7.

57. Bakay M, Pandey R, Hakonarson H. Genes involved in type 1 diabetes: an update. Genes (Basel). 2013:4:499-521.

58. Kato N. Insights into the genetic basis of type 2 diabetes. J Diabetes Investig. 2013;4:233-44.

59. Tabassum R, Chauhan G, Dwivedi OP, Mahajan A, Jaiswal A, Kaur I, et al. Genome-wide association study for type 2 diabetes in Indians identifies a new susceptibility locus at 2q21. Diabetes. 2013;62:977-86.

60. Lkhagvadorj S, Qu L, Cai W, Couture OP, Barb CR, Hausman GJ, et al. Gene expression profiling of the short-term adaptive response to acute caloric restriction in liver and adipose tissues of pigs differing in feed efficiency. Am J Physiol Regul Integr Comp Physiol. 2010:298:R494-507.

61. Speer G, Cseh K, Winkler G, Vargha P, Braun E, Takacs I, et al. Vitamin D and estrogen receptor gene polymorphisms in type 2 diabetes mellitus and in android type obesity. Eur J Endocrinol. 2001;144:385-9. 
62. Johswich A, Longuet C, Pawling J, Abdel Rahman A, Ryczko M, Drucker DJ, et al. N-glycan remodeling on glucagon receptor is an effector of nutrient sensing by the hexosamine biosynthesis pathway. J Biol Chem. 2014;289: 15927-41.

63. Do DN, Strathe AB, Ostersen T, Jensen J, Thomas M, Kadarmideen HN. Genome-wide association study reveals genetic architecture of eating behavior in pigs and its implications for humans obesity by comparative mapping. PLoS ONE. 2013;8:e71509.

64. Li X, Yang S, Tang Z, Li K, Rothschild MF, Liu B, et al. Genome-wide scans to detect positive selection in Large White and Tongcheng pigs. Anim Genet. 2014:45:329-39.

65. Madhur MS, Funt SA, Li L, Vinh A, Chen W, Lob HE, et al. Role of interleukin 17 in inflammation, atherosclerosis, and vascular function in apolipoprotein e-deficient mice. Arterioscler Thromb Vasc Biol. 2011;31:1565-72.

66. Galgani M, Matarese G. Editorial: acute inflammation in obesity: IL-17A in the middle of the battle. J Leukoc Biol. 2010;87:17-8.

67. Qi Q, Menzaghi C, Smith S, Liang L, de Rekeneire N, Garcia ME, et al Genome-wide association analysis identifies TYW3/CRYZ and NDST4 loci associated with circulating resistin levels. Hum Mol Genet. 2012;21:4774-80.

68. Abbott KL, Troupe K, Lee I, Pierce M. Integrin-dependent neuroblastoma cell adhesion and migration on laminin is regulated by expression levels of two enzymes in the O-mannosyl-linked glycosylation pathway, PomGnT1 and GnT-Vb. Exp Cell Res. 2006;312:2837-50.

69. Matsui T, Noguchi K, Fukuda M. Dennd3 functions as a guanine nucleotide exchange factor for small GTPase Rab12 in mouse embryonic fibroblasts. J Biol Chem. 2014;289:13986-95.

70. Boender AJ, van Rozen AJ, Adan RA. Nutritional state affects the expression of the obesity-associated genes Etv5, Faim2, Fto, and Negr1. Obesity (Silver Spring). 2012;20:2420-5.

71. Thorleifsson G, Walters GB, Gudbjartsson DF, Steinthorsdottir V, Sulem P, Helgadottir A, et al. Genome-wide association yields new sequence variants at seven loci that associate with measures of obesity. Nat Genet. 2009:41: $18-24$.

72. Bauer F, Elbers CC, Adan RA, Loos RJ, Onland-Moret NC, Grobbee DE, et al. Obesity genes identified in genome-wide association studies are associated with adiposity measures and potentially with nutrient-specific food preference. Am J Clin Nutr. 2009;90:951-9.

73. Ljubicic S, Bezzi P, Brajkovic S, Nesca V, Guay C, Ohbayashi N, et al. The GTPase Rab37 Participates in the Control of Insulin Exocytosis. PLoS ONE. 2013;8:e68255

74. Muhammad E, Leventhal N, Parvari G, Hanukoglu A, Hanukoglu I, ChalifaCaspi $V$, et al. Autosomal recessive hyponatremia due to isolated salt wasting in sweat associated with a mutation in the active site of Carbonic Anhydrase 12. Hum Genet. 2011;129:397-405.

75. Yang X, Deignan JL, Qi H, Zhu J, Qian S, Zhong J, et al. Validation of candidate causal genes for obesity that affect shared metabolic pathways and networks. Nature Genet. 2009:41:415-23.

76. Efeyan A, Comb WC, Sabatini DM. Nutrient-sensing mechanisms and pathways. Nature. 2015:517:302-10

77. Grossman SP. The role of glucose, insulin and glucagon in the regulation of food intake and body weight. Neurosci Biobehav Rev. 1986;10:295-315.

78. Chan JC, Knudson O, Wu F, Morser J, Dole WP, Wu Q. Hypertension in mice lacking the proatrial natriuretic peptide convertase corin. Proc Natl Acad Sci U S A. 2005;102:785-90.

79. Rankinen T, Zuberi A, Chagnon YC, Weisnagel SJ, Argyropoulos G, Walts B, et al. The human obesity gene map: the 2005 update. Obesity (Silver Spring). 2006;14:529-644

80. Santana MH, Utsunomiya YT, Neves HH, Gomes RC, Garcia JF, Fukumasu H, et al. Genome-wide association analysis of feed intake and residual feed intake in Nellore cattle. BMC Genet. 2014;15:21.

81. Cabrera CP, Dunn IC, Fell M, Wilson PW, Burt DW, Waddington D, et al. Complex traits analysis of chicken growth using targeted genetical genomics. Anim Genet. 2012;43:163-71.

82. Karisa BK, Thomson J, Wang Z, Stothard P, Moore SS, Plastow GS. Candidate genes and single nucleotide polymorphisms associated with variation in residual feed intake in beef cattle. J Anim Sci. 2013:91:3502-13.

83. Taneera J, Lang S, Sharma A, Fadista J, Zhou Y, Ahlqvist E, et al. A systems genetics approach identifies genes and pathways for type 2 diabetes in human islets. Cell Metab. 2012;16:122-34.

84. Stylianou IM, Clinton M, Keightley PD, Pritchard C, Tymowska-Lalanne Z, Bünger $L$, et al. Microarray gene expression analysis of the Fob3b obesity
QTL identifies positional candidate gene Sqle and perturbed cholestero and glycolysis pathways. Physiol Genomics. 2005;20:224-32.

85. Prevorsek Z, Gorjanc G, Paigen B, Horvat S. Congenic and bioinformatics analyses resolved a major-effect Fob3b QTL on mouse Chr 15 into two closely linked loci. Mamm Genome. 2010;21:172-85.

86. lezzi M, Theander S, Janz R, Loze C, Wollheim CB. SV2A and SV2C are not vesicular Ca2+ transporters but control glucose-evoked granule recruitment. J Cell Sci. 2005;118:5647-60.

87. Sancak, Ö. Single nucleotide polymorphisms associated with dietary weight loss. Google Patents. 2014. http://www.google.com/patents/ EP2510115B1?cl=en. Accessed 19 Oct 2016

88. Kim GH, Park EC, Yun SH, Hong Y, Lee DG, Shin EY, et al. Proteomic and bioinformatic analysis of membrane proteome in type 2 diabetic mouse liver. Proteomics. 2013;13:1164-79.

89. Valera Mora ME, Scarfone A, Calvani M, Greco AV, Mingrone G. Insulin clearance in obesity. J Am Coll Nutr. 2003;22:487-93.

90. Karamohamed S, Demissie S, Volcjak J, Liu C, Heard-Costa N, Liu J, et al. Polymorphisms in the insulin-degrading enzyme gene are associated with type 2 diabetes in men from the NHLBI Framingham Heart Study. Diabetes. 2003;52:1562-7

91. Simoncic M, Rezen T, Juvan P, Fievet C, Staels B, Rozman D, et al. Transcriptome analysis revealed association of some $\mathrm{P} 450$ genes with obesity in a polygenic obese mouse model. Acta Chim Slov. 2008;55:101-10.

92. Tizioto PC, Decker JE, Taylor JF, Schnabel RD, Mudadu MA, Silva FL, et al. Genome scan for meat quality traits in Nelore beef cattle. Physiol Genomics. 2013;45:1012-20.

93. Zhang H, Wang SZ, Wang ZP, Da Y, Wang N, Hu XX, et al. A genome-wide scan of selective sweeps in two broiler chicken lines divergently selected for abdominal fat content. BMC Genomics. 2012;13:704.

94. Pedersen L, Olsen CH, Pedersen BK, Hojman P. Muscle-derived expression of the chemokine CXCL1 attenuates diet-induced obesity and improves fatty acid oxidation in the muscle. Am J Physiol Endocrinol Metab. 2012;302:E831-40

95. Gao D, Nong $S$, Huang $X, L u ~ Y, Z$ Zhao H, Lin $Y$, et al. The effects of palmitate on hepatic insulin resistance are mediated by NADPH Oxidase 3-derived reactive oxygen species through JNK and p38MAPK pathways. J Biol Chem. 2010;285:29965-73.

96. Lindholm-Perry AK, Kern RJ, Kuehn LA, Snelling WM, Miles JR, Oliver WT, et al. Differences in transcript abundance of genes on BTA15 located within a region associated with gain in beef steers. Gene. 2015;572:42-8.

97. Reddy MV, Wang H, Liu S, Bode B, Reed JC, Steed RD, et al. Association between type 1 diabetes and GWAS SNPs in the southeast US Caucasian population. Genes Immun. 2011;12:208-12.

98. Pyun JA, Kim S, Cha DH, Kwack K. Epistasis between IGF2R and ADAMTS19 polymorphisms associates with premature ovarian failure. Hum Reprod. 2013:28:3146-54.

99. Nafikov RA, Schoonmaker JP, Korn KT, Noack K, Garrick DJ, Koehler KJ, et al. Association of polymorphisms in solute carrier family 27 , isoform A6 (SLC27A6) and fatty acid-binding protein-3 and fatty acid-binding protein-4 (FABP3 and FABP4) with fatty acid composition of bovine milk. J Dairy Sci. 2013;96:6007-21.

100. Onteru SK, Gorbach DM, Young JM, Garrick DJ, Dekkers JC, Rothschild MF. Whole genome association studies of residual feed intake and related traits in the pig. PLoS ONE. 2013;8:e61756.

101. Oñate B, Vilahur G, Camino-López S, Díez-Caballero A, Ballesta-López C, Ybarra J, et al. Stem cells isolated from adipose tissue of obese patients show changes in their transcriptomic profile that indicate loss in stemcellness and increased commitment to an adipocyte-like phenotype. BMC Genomics. 2013;14:625

102. Opleta-Madsen K, Hardin J, Gall DG. Epidermal growth factor upregulates intestinal electrolyte and nutrient transport. Am J Physiol. 1991;260:G807-14.

103. Bernard C, Cassar-Malek I, Renand G, Hocquette JF. Changes in muscle gene expression related to metabolism according to growth potential in young bulls. Meat Sci. 2009:82:205-12.

104. Hanks LJ, Casazza K, Judd SE, Jenny NS, Gutiérrez OM. Associations of fibroblast growth factor-23 with markers of inflammation, insulin resistance and obesity in adults. PLOS ONE. 2015;10:e0122885.

105. Elbein SC, Kern PA, Rasouli N, Yao-Borengasser A, Sharma NK, Das SK. Global gene expression profiles of subcutaneous adipose and muscle from glucose-tolerant, insulin-sensitive, and insulin-resistant individuals matched for BMI. Diabetes. 2011;60:1019-29. 
106. Patwari P, Emilsson V, Schadt EE, Chutkow WA, Lee $S$, Marsili A, et al. The arrestin domain-containing 3 protein regulates body mass and energy expenditure. Cell Metab. 2011;14:671-83.

107. Heinonen S, Saarinen L, Naukkarinen J, Rodríguez A, Frühbeck G, Hakkarainen A, et al. Adipocyte morphology and implications for metabolic derangements in acquired obesity. Int J Obes (Lond). 2014;38:1423-31.

108. Doran AG, Berry DP, Creevey CJ. Whole genome association study identifies regions of the bovine genome and biological pathways involved in carcass trait performance in Holstein-Friesian cattle. BMC Genomics. 2014;15:837.

109. Hu Z-L, Reecy JM. Animal QTLdb: beyond a repository. Mamm Genome. 2007;18:1-4

110. Zhang Q, Ma Y, Wang X, Zhang Y, Zhao X. Identification of copy number variations in Qinchuan cattle using BovineHD genotyping beadchip array. Mol Genet Genomics. 2015;290:319-27.

111. Geay F, Ferraresso S, Zambonino-Infante JL, Bargelloni L, Quentel C, Vandeputte $M$, et al. Effects of the total replacement of fish-based diet with plant-based diet on the hepatic transcriptome of two European sea bass (Dicentrarchus labrax) half-sib families showing different growth rates with the plant-based diet. BMC Genomics. 2011;12:522.

112. Frisdal E, Le Lay S, Hooton H, Poupel L, Olivier M, Alili R, et al. Adipocyte ATP-binding cassette G1 promotes triglyceride storage, fat mass growth, and human obesity. Diabetes. 2015;64:840-55.

113. Ge H, Gardner J, Wu X, Rulifson I, Wang J, Xiong Y, et al. Trefoil Factor 3 (TFF3) is regulated by food intake, improves glucose tolerance and induces mucinous metaplasia. PLoS ONE. 2015;10:e0126924.

114. Ma J, Yang J, Zhou L, Zhang Z, Ma H, Xie X, et al. Genome-wide association study of meat quality traits in a White Duroc $\times$ Erhualian F2 intercross and Chinese Sutai pigs. PLoS ONE. 2013;8:e64047.

115. Wang X, Zhu H, Snieder H, Su S, Munn D, Harshfield G, et al. Obesity related methylation changes in DNA of peripheral blood leukocytes. BMC Med. 2010;8:87.

116. Kilzikaya K, Tait RG, Garrick DJ, Fernando RL, Reecy JM. Genome-wide association study of infectious bovine keratoconjunctivitis in Angus cattle. BMC Genet. 2013;14:23.

117. Yu B, Zheng Y, Alexander D, Manolio TA, Alonso A, Nettleton JA, et al. Genome-wide association study of a heart failure related metabolomic profile among African Americans in the Atherosclerosis Risk in Communities (ARIC) study. Genet Epidemiol. 2013;37:840-5.

118. Collares CV, Evangelista AF, Xavier DJ, Rassi DM, Arns T, Foss-Freitas MC, et al. Identifying common and specific microRNAs expressed in peripheral blood mononuclear cell of type 1, type 2, and gestational diabetes mellitus patients. BMC Res Notes. 2013;6:491.

119. Southey BR, Rodriguez-Zas SL, Sweedler JV. Characterization of the prohormone complement in cattle using genomic libraries and cleavage prediction approaches. BMC Genomics. 2009;10:228.

120. Sainsbury A, Lin S, McNamara K, Slack K, Enriquez R, Lee NJ, et al. Dynorphin knockout reduces fat mass and increases weight loss during fasting in mice. Mol Endocrinol. 2007;21:1722-35.

121. McManus DD, Beaulieu LM, Mick E, Tanriverdi K, Larson MG, Keaney JF, et al. Relationship among circulating inflammatory proteins, platelet gene expression, and cardiovascular risk. Arterioscler Thromb Vasc Biol. 2013;33:2666-73.

122. Jiang BH, Chen WY, Li HY, Chien Y, Chang WC, Hsieh PC, et al. CHD1L regulated $P A R P 1-d r i v e n$ pluripotency and chromatin remodeling during the early-stage cell reprogramming. Stem Cells. 2015;33:2961-72.

123. Cheng W, Su Y, Xu F. CHD1L: a novel oncogene. Mol Cancer. 2013;12:170.

124. Barendse WJ, Bunch R, Thomas M, Armitage S, Baud S, Donaldson N. The TG5 thyroglobulin gene test for a marbling quantitative trait loci evaluated in feedlot cattle. Aust J Exp Agric. 2004;44:669-74.

125. Bovine HapMap Consortium, Gibbs RA, Taylor JF, Van Tassell CP, Barendse W, Eversole KA, et al. Genome-wide survey of SNP variation uncovers the genetic structure of cattle breeds. Science. 2009;324:528-32.

126. Kärst S, Arends D, Heise S, Trost J, Yaspo ML, Amstislavskiy V, et al. The direction of cross affects obesity after puberty in male but not female offspring. BMC Genomics. 2015;16:904

127. Schmitt AO, Al-Hasani H, Cheverud JM, Pomp D, Bünger L, Brockmann GA. Fine mapping of mouse QTLs for fatness using SNP data. OMICS. 2007;11:341-50

128. Huffman JE, Albrecht E, Teumer A, Mangino M, Kapur K, Johnson T, et al. Modulation of genetic associations with serum urate levels by body-massindex in humans. PLoS ONE. 2015;10:e0119752.
129. Durgan DJ, Smith JK, Hotze MA, Egbejimi O, Cuthbert KD, Zaha VG, et al. Distinct transcriptional regulation of long-chain acyl-CoA synthetase isoforms and cytosolic thioesterase 1 in the rodent heart by fatty acids and insulin. Am J Physiol Heart Circ Physiol. 2006;290:H2480-97.

130. Chen J, Meng Y, Zhou J, Zhuo M, Ling F, Zhang Y, et al. Identifying candidate genes for Type 2 Diabetes Mellitus and obesity through gene expression profiling in multiple tissues or cells. J Diabetes Res. 2013;2013:970435.

131. Stewart TP, Kim HY, Saxton AM, Kim JH. Genetic and genomic analysis of hyperlipidemia, obesity and diabetes using (C57BL/6J XTALLYHO/JngJ) F2 mice. BMC Genomics. 2010;11:713.

132. Chen Y, Zhu J, Lum PY, Yang X, Pinto S, MacNeil DJ, et al. Variations in DNA elucidate molecular networks that cause disease. Nature. 2008;452:429-35.

133. Latreille M, Laberge MK, Bourret G, Yamani L, Larose L. Deletion of Nck1 attenuates hepatic ER stress signaling and improves glucose tolerance and insulin signaling in liver of obese mice. J Physiol Endocrinol Metab. 2011;300:E423-34

134. Morita M, Suzuki T, Nakamura T, Yokoyama K, Miyasaka T, Yamamoto T. Depletion of mammalian CCR4b deadenylase triggers elevation of the p27Kip1 mRNA level and impairs cell growth. Mol Cell Biol. 2007;27:4980-90.

135. Mittal S, Aslam A, Doidge R, Medica R, Winkler SG. The Ccr4a (CNOT6) and Ccr4b (CNOT6L) deadenylase subunits of the human Ccr4-Not complex contribute to the prevention of cell death senescence. Mol Biol Cell. 2011; 22:748-58.

136. Scheffer LL, Sreetama SC, Sharma N, Medikayala S, Brown KJ, Defour A, et al. Mechanism of $\mathrm{Ca}^{2+}$-triggered ESCRT assembly and regulation of cell membrane repair. Nat Commun. 2014;5:5646.

137. Yang W, Shen Z, Martens $H$. An energy-rich diet enhances expression of $\mathrm{Na}(+) / \mathrm{H}(+)$ exchanger isoform 1 and 3 messenger RNA in rumen epithelium of goat. J Anim Sci. 2012;90:307-17.

138. Bouchard L, Bouchard C, Chagnon YC, Perusse L. Evidence of linkage and association with body fatness and abdominal fat on chromosome $15 q 26$. Obesity (Silver Spring). 2007;15:2061-70.

139. Gardiner JV, Beale KE, Roy D, Boughton CK, Bataveljic A, Campbell DC, et al. Cerebellin1 is a novel orexigenic peptide. Diabetes Obes Metab. 2010;12: 883-90

140. Abo-Ismail MK, Vander Voort G, Squires JJ, Swanson KC, Mandell IB, Liao X, et al. Single nucleotide polymorphisms for feed efficiency and performance in crossbred beef cattle. BMC Genet. 2014;15:14.

141. Liu M, Li M, Liu J, Wang H, Zhong D, Zhou H, et al. Elevated urinary urea by high-protein diet could be one of the inducements of bladder disorders. J Transl Med. 2016;14:53.

142. Need AC, Ahmadi KR, Spector TD, Goldstein DB. Obesity is associated with genetic variants that alter dopamine availability. Ann Hum Genet. 2006;70: 293-303.

143. Sharma NK, Das SK, Mondal AK, Hackney OG, Chu WS, Kern PA, et al. Endoplasmic reticulum stress markers are associated with obesity in nondiabetic subjects. J Clin Endocrinol Metab. 2008:93:4532-41.

144. Linnemann A, van der Ven PF, Vakeel P, Albinus B, Simonis D, Bendas G, et al. The sarcomeric Z-disc component myopodin is a multiadapter protein that interacts with filamin and alpha-actinin. Eur J Cell Biol. 2010;89:681-92.

145. Wang HB, Li H, Wang QG, Zhang XY, Wang SZ, Wang YX, et al. Profiling of chicken adipose tissue gene expression by genome array. BMC Genomics. 2007;8:193.

146. van Kuilenburg AB, Dobritzsch D, Meijer J, Meinsma R, Benoist JF, Assmann $B$, et al. Dihydropyrimidinase deficiency: Phenotype, genotype and structural consequences in 17 patients. Biochim Biophys Acta. 1802;2010:639-48.

147. Reiff RE, Ali BR, Baron B, Yu TW, Ben-Salem S, Coulter ME, et al. METTL23, a transcriptional partner of GABPA, is essential for human cognition. Hum Mol Genet. 2014;23:3456-66.

148. Slocum N, Durrant JR, Bailey D, Yoon L, Jordan H, Barton J, et al. Responses of brown adipose tissue to diet-induced obesity, exercise, dietary restriction and ephedrine treatment. Exp Toxicol Pathol. 2013;65:549-57.

149. Hu YJ, Belaghzal H, Hsiao WY, Qi J, Bradner JE, Guertin DA, et al. Transcriptional and post-transcriptional control of adipocyte differentiation by Jumonji domain-containing protein 6. Nucleic Acids Res. 2015;43:7790-804.

150. de Camargo GMF, Aspilcueta-Borquis RR, Fortes MRS, Porto-Neto R, Cardoso DF, Santos DJA, et al. Prospecting major genes in dairy buffaloes. BMC Genomics. 2015;16:872.

151. Sato Y, Iketani M, Kurihara Y, Yamaguchi M, Yamashita N, Nakamura F, et al. Cartilage acidic protein-1B (LOTUS), an endogenous Nogo receptor antagonist for axon tract formation. Science. 2011;333(6043):769-73. 
152. Day FR, Bulik-Sullivan B, Hinds DA, Finucane HK, Murabito JM, Tung JY, et al. Shared genetic aetiology of puberty timing between sexes and with healthrelated outcomes. Nat Commun. 2015;6:8842.

153. Ohlsson C, Wallaschofski H, Lunetta KL, Stolk L, Perry JR, Koster A, et al. Genetic determinants of serum testosterone concentrations in men. PLoS Genet. 2011;7(10):e1002313.

154. Utsunomiya YT, do Carmo AS, Carvalheiro R, Neves HH, Matos MC, Zavarez LB, et al. Genome-wide association study for birth weight in Nellore cattle points to previously described orthologous genes affecting human and bovine height. BMC Genet. 2013;14:52.

155. Gudbjartsson DF, Walters GB, Thorleifsson G, Stefansson H, Halldorsson BV, Zusmanovich $\mathrm{P}$, et al. Many sequence variants affecting diversity of adult human height. Nat Genet. 2008;40:609-15.

156. Pryce JE, Hayes BJ, Bolormaa S, Goddard ME. Polymorphic regions affecting human height also control stature in cattle. Genetics. 2011:187:981-4.

157. Kogelman L, Zhernakova DV, Westra HJ, Cirera S, Fredholm M, Franke L, et al. An integrative systems genetics approach reveals potential causal genes and pathways related to obesity. Genome Med. 2015;7:105.

158. Kang HJ, Kawasawa Yl, Cheng F, Zhu Y, Xu X, Li M, et al. Spatio-temporal transcriptome of the human brain. Nature. 2011;478:483-9.

159. Shi L, Chang X, Zhang P, Coba MP, Lu W, Wang K. The functional genetic link of NLGN4X knockdown and neurodevelopment in neural stem cells. Hum Mol Genet. 2013;22:3749-60.

160. Asou H, Matsui H, Ozaki Y, Nagamachi A, Nakamura M, Aki D, et al. Identification of a common microdeletion cluster in 7q21.3 subband among patients with myeloid leukemia and myelodysplastic syndrome. Biochem Biophys Res Commun. 2009;383:245-51.

161. Cooper JD, Smyth DJ, Bailey R, Payne F, Downes K, Godfrey LM, et al. The candidate genes TAF5L, TCF7, PDCD1, IL6 and ICAM1 cannot be excluded from having effects in type 1 diabetes. BMC Med Genet. 2007:8:71.

162. Mahajan A, Sim X, Ng HJ, Manning A, Rivas MA, Highland HM, et al. Identification and functional characterization of G6PC2 coding variants influencing glycemic traits define an effector transcript at the G6PC2-ABCB11 locus. PLoS Genet. 2015;11:e1004876.

163. Lindholm-Perry AK, Sexten AK, Kuehn LA, Smith TP, King DA, Shackelford SD, et al. Association, effects and validation of polymorphisms within the NCAPG - LCORL locus located on BTA6 with feed intake, gain, meat and carcass traits in beef cattle. BMC Genet. 2011;12:103.

164. Hoshiba H, Setoguchi K, Watanabe T, Kinoshita A, Mizoshita K, Sugimoto Y, et al. Comparison of the effects explained by variations in the bovine PLAG1 and NCAPG genes on daily body weight gain, linear skeletal measurements and carcass traits in Japanese Black steers from a progeny testing program. Anim Sci J. 2013;84:529-34.

165. Fortes MRS, Lehnert SA, Bolormaa S, Reich C, Fordyce G, Corbet NJ, et al. Finding genes for economically important traits: Brahman cattle puberty. Anim Prod Sci. 2012;52:143-50

166. Fan B, Onteru SK, Du ZQ, Garrick DJ, Stalder K, Rothschild MF. Genomewide association study identifies loci for body composition and structural soundness traits in pigs. PLOS ONE. 2011;6:e14726.

167. Anveden A, Sjöholm K, Jacobson P, Palsdottir V, Walley AJ, Froguel P, et al. ITIH-5 expression in human adipose tissue is increased in obesity. Obesity (Silver Spring). 2012;20:708-14.

168. Manning AK, Hivert MF, Scott RA, Grimsby JL, Bouatia-Naji N, Chen H, et al. A genome-wide approach accounting for body mass index identifies genetic variants influencing fasting glycemic traits and insulin resistance. Nat Genet. 2012;44:659-69.

169. Neibergs HL, Seabury CM, Wojtowicz AJ, Wang Z, Scraggs E, Kiser JN, et al. Susceptibility loci revealed for bovine respiratory disease complex in preweaned Holstein calves. BMC Genomics. 2014;15:1164.

170. Davis BW, Seabury CM, Brashear WA, Li G, Roelke-Parker M, Murphy WJ. Mechanisms underlying mammalian hybrid sterility in two feline interspecies models. Mol Biol Evol. 2015;32:2534-46.

171. Kang HM, Zaitlen NA, Wade CM, Kirby A, Heckerman D, Daly MJ, et al. Efficient control of population structure in model organism association mapping. Genetics. 2008;178:709-1723.

\section{Submit your next manuscript to BioMed Central and we will help you at every step:}

- We accept pre-submission inquiries

- Our selector tool helps you to find the most relevant journal

- We provide round the clock customer support

- Convenient online submission

- Thorough peer review

- Inclusion in PubMed and all major indexing services

- Maximum visibility for your research

Submit your manuscript at www.biomedcentral.com/submit

) Biomed Central 